\title{
Disentangling the role of prefire vegetation vs. burning conditions on fire severity in a large forest fire in SE Spain
}

\author{
O. Viedma ${ }^{\mathrm{a}, *}$, F. Chico ${ }^{\mathrm{b}}$, J.J. Fernández ${ }^{\mathrm{b}}$, C. Madrigal ${ }^{\mathrm{b}}$, H.D. Safford ${ }^{\text {c,d }}$, J.M. Moreno ${ }^{\mathrm{a}}$ \\ ${ }^{\text {a }}$ Departamento de Ciencias Ambientales, Universidad de Castilla-La Mancha, Avda. Carlos III s/n, 45071 Toledo, Spain \\ ${ }^{\mathrm{b}}$ Gestión Ambiental de Castilla-La Mancha, S.A. (GEACAM), C/ Río Cabriel, 44, 45007 Toledo, Spain

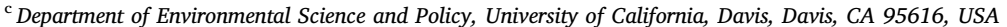 \\ ${ }^{\mathrm{d}}$ USDA Forest Service, Pacific Southwest Region, Vallejo, CA 94592, USA
}

\section{A R T I C L E I N F O}

\section{Keywords:}

Fire severity

LiDAR

Sentinel 2 MSI

Landsat 8 OLI

Prefire vegetation

Fire propagation

Fire weather

Topography

Fire history

\begin{abstract}
A B S T R A C T
Fire severity is a function of dynamic interactions between vegetation and burning conditions. To understand the factors that control it, accurate methods for estimating prefire vegetation structure and composition as well as fire propagation conditions are required. Here we analyzed the spatial variability of fire severity in a mixedseverity fire (3217 ha) that occurred in southeast Spain (Yeste, Albacete) from 27th July to 1th August 2017, burning mostly a pine woodland, including part of an earlier fire in 1994. Fire severity was estimated using three satellite-based indices derived from the Normalized Burn Ratio (NBR) using Sentinel 2 and Landsat 8 images from the dates before and immediately after fire. The field-based Composite Burn Index (CBI) was used for validation. Prefire vegetation conditions and fuel models were derived from LiDAR metrics and other vegetation data. Fire propagation conditions were estimated based on a fire progression map provided by the Forestry Services of Castilla-La Mancha. In addition, hourly fire weather and aligned (i.e., in the sense of the propagating fire-front) slope and wind speed were calculated for each burning period. Regression models using different spectral fire severity indices and their driving factors were obtained applying Boosted Regression Trees (BRTs). Fire severity was highly predicted by both burning conditions and prefire vegetation (mean adjusted $\mathrm{R}^{2}$ [Adj. $\mathrm{R}^{2}$ ]: $86 \% \pm 0.04$ and $68 \% \pm 0.05$ for training and validation sets, respectively). Alone, burning conditions explained more variance than LiDAR metrics and vegetation separately. The single variables that contributed most to the models were the rate of spread of the fire-front, biomass proxies (i.e., Leaf Area Index [LAI] and fraction of Photosynthetically Active Radiation [fPAR]) and understory vegetation (i.e., density of LiDAR points 1-2 m). Higher fire severity occurred in areas burning uphill, with a high rate of spread driven by high velocity winds and under high maximum temperature. Fire severity was high in wooded stands that were heterogeneous in height, composed by scattered and small Pinus halepensis trees, with high and homogeneous understory cover. In contrast, lower fire severity occurred in mature stands dominated by tall Pinus pinaster and Pinus nigra trees. There were strong interactions between vegetation, weather, fire-aligned topography and rate of spread. Because vegetation variables were important drivers of fire severity, even under extreme fire weather conditions, fuel management treatments to limit fire severity and, potentially, fire size should be implemented.
\end{abstract}

\section{Introduction}

Fire severity, defined as the degree of environmental change caused by fire (i.e., the loss of organic matter, both aboveground and belowground) (Keeley, 2009; Morgan et al., 2014), can have multiple ecological implications. Fire severity is directly correlated with carbon emissions (Conard et al., 2002; Meigs et al., 2009; Veraverbeke et al., 2015; Harris et al., 2019), and it has significant impacts on vegetation and soils and may greatly influence ecosystem response trajectories (Moreno and Oechel, 1993; Holden et al., 2009; Clarke et al., 2013; Shive et al., 2018), postfire soil erosion (Marion et al., 1991; Robichaud, 2009), biodiversity (White et al., 2016; Miller et al., 2018) and also water quality (Shakesby et al., 2003; Doerr et al., 2006). Moreover, fire severity affects landscape heterogeneity (e.g., unburned islands), with implications for biodiversity and multiple ecosystem processes including future disturbances (e.g., Turner et al., 1994;

\footnotetext{
* Corresponding author.

E-mail addresses: olga.viedma@uclm.es (O. Viedma), fernando.chico@geacam.com (F. Chico), juanjofernandez@geacam.com (J.J. Fernández), carlos.madrigal@geacam.com (C. Madrigal), hugh.safford@usda.gov (H.D. Safford), josem.moreno@uclm.es (J.M. Moreno).
} 
Román-Cuesta et al., 2009; Steel et al., 2018; Collins et al., 2019). Given the large damage of high-severity fires, accurately predicting the spatial variability of fire severity within fire perimeters is essential for prioritizing areas of fuel treatments (e.g., Fernandes and Rigolot, 2007), obtaining more precise quantification of fire-carbon balance (e.g., Meigs et al., 2009; Veraverbeke et al., 2015), and predicting ecosystem impacts (Welch et al., 2016; Shive et al., 2018), among other issues. However, to understand the factors that control fire severity, accurate methods for estimating prefire vegetation (i.e., structure, composition and moisture content) as well as burning conditions - including fire weather, topography and fire progression - are required. Fire severity may exhibit considerable spatial variability within a fire perimeter (Turner et al., 1994; Román-Cuesta et al., 2009; Collins et al., 2019) and the degree to which variability is driven by differences in fuels, topography or weather can vary, owing to complex interactions among these factors (e.g., Bradstock et al., 2010; Price and Bradstock, 2012; Viedma et al., 2015).

It has been shown that fire severity strongly depends both on the dominant plant species and forest structure (González et al., 2007; Fernandes et al., 2010; Miller et al., 2009, 2012; Mallek et al., 2013; DeSiervo et al., 2015). However, it is common in studies focusing on the spatial variability of fire severity to represent vegetation and fuels only by coarse-scale maps of vegetation type or land cover (e.g., Hammill and Bradstock, 2006; Lee et al., 2008), sometimes enhanced with a few stand structural variables measured in the field (e.g., Broncano and Retana, 2004; Fernandes et al., 2010; Collins et al., 2007; Thompson and Spies, 2009; Viedma et al., 2015). The growing availability of Light Detection and Ranging (LiDAR) data offers opportunities to obtain information on the horizontal and vertical structure of prefire vegetation, which can help to greatly improve our understanding of how vegetation and fuels may govern fire severity. Nonetheless, to this point few studies of fire severity have complemented coarse-scale vegetation information with LiDAR data, partly because such data - even when available - are rarely collected at the right time for a particular fire (e.g., Wulder et al., 2009; Fernández-Alonso et al., 2017; García-Llamas et al., 2019).

Fuel moisture content (FMC) has a critical role in fire severity because the amount of water in fuels is directly related to fire intensity (Agee et al., 2002). Estimations of FMC from weather variables are reasonably well suited for dead fuels, because their water content is highly related to atmospheric conditions. However, in live fuels, species physiological characteristics and adaptation to drought imply greater variability of moisture conditions with the same meteorological conditions (Yebra et al., 2008). Nevertheless, when detailed temporal weather data during the fire event and prefire vegetation type-biomassstructure are known, FMC can be implicitly estimated by from such proxies (Camia et al., 1999; Pereira et al., 2005).

Vegetation and fuels are also greatly affected by the fire history of a site. The legacy of past fires may thus affect subsequent fire severity of a new fire (e.g., Collins et al., 2007; van Wagtendonk et al., 2012; Price and Bradstock, 2012; Parks et al., 2014; Clarke et al., 2014; Steel et al., 2015; Coppoletta et al., 2016; Harris and Taylor, 2017; Barker and Price, 2018), depending on the vegetation in question and the time allowed for fuels to grow. However, detailed fire history mapping is relatively new, and for much of the world only a few decades of digital data are available.

Topographic effects on fire severity are complex and highly variable, and have often given contradictory results, in part due to the complex interactions of topography with fuels (e.g., Broncano and Retana, 2004; Holden et al., 2009; Lentile et al., 2006; Coen et al., 2018) and fire behaviour (e.g., Oliveras et al., 2009; Viedma et al., 2015). Some studies have reported strong control of topography over fire severity even under extreme fire weather conditions (e.g., Holden et al., 2009; Bradstock et al., 2010; Dillon et al., 2011; Viedma et al., 2015; Birch et al., 2015; Harris and Taylor, 2015, 2017; Fang et al., 2015, 2018; Zald and Dunn, 2018), while others have shown that extreme fire weather conditions can override or shift the relationships between topography and fire severity (e.g., Collins et al., 2007; Clarke et al., 2014; Fernández-Alonso et al., 2017; Zald and Dunn, 2018; Fernandes et al., 2019). However, it can be difficult to determine the robustness of some assessments because few studies to date have incorporated fire progression data, which would allow considering the alignment between topographical features and the propagating firefront (see, e,g., Viedma et al., 2015). Precise maps of fire spread can solve this problem, but they are either not available or only available for recent fires in most parts of the world. Using topography without considering how it interacts with fire propagation can produce spurious results. Some recent studies have considered interactions between topography and wind but not fire spread (Lecina-Diaz et al., 2014; Birch et al., 2015; Fernández-Alonso et al., 2017).

Synoptic patterns associated with large summer forest fires in the western Mediterranean region are mainly related to anomalous advection of hot and dry air from Northern Africa (Pereira et al., 2005; Trigo et al., 2006; Amraoui et al., 2015). Vegetation hydric and thermal stress, particularly during severe heatwaves, are highly correlated with the occurrence of the most devastating fires in the Mediterranean (Lindner et al., 2010). Extreme fire weather (e.g., strong winds, high temperature, low air humidity) - which increases the efficiency of heat transfer and the rate of spread while reducing fuel moisture at the same time (e.g., Fernandes et al., 2004; Cruz and Alexander, 2013) - is often considered to have a predominant influence on fire severity (Bradstock et al., 2010; Coen et al., 2018; Jones et al., 2009). Nevertheless, it is difficult to assess what is extreme, as it is a qualitative concept that varies across different regions (for example, Australian savannas vs. boreal forests) (e.g., Bradstock et al., 2010; Thompson and Spies, 2009, 2010; Coen et al., 2018). As with vegetation and fire progression data, the resolution of weather data can confound an analysis. Data qualityrelated reasons for the low explanatory power of weather variables can include coarse spatial (e.g., 4-km) (e.g., Birch et al., 2015) and temporal resolutions (e.g., daily or 10-day) (Thompson and Spies, 2009, 2010; Dillon et al., 2011), low variability in the data (Parks et al., 2015; Whitman et al., 2018), and distant weather stations that poorly reflect local conditions (Collins et al., 2007; Zald and Dunn, 2018). For a highly credible understanding of the role of weather on fire severity it is necessary to study the impact of different variables at high temporal and spatial resolutions, with a marked attention to the wind speed and direction (Viedma et al., 2015; Lahaye et al., 2018).

A rarely considered, but theoretically important, factor in determining fire severity is the location of burning with respect to advancing fire front (head vs. flank vs. rear) (e.g., Ryan, 2002; Oliveras et al., 2009) and the varying rate of spread of the fire-front (e.g., Viedma et al., 2015). Accordingly, it has been shown that heading fire (i.e., with the wind) burns upslope with higher intensity than backing fire (against the wind), that burns downslope, or flanking fire which burns perpendicular to the wind's direction (Oliveras et al., 2009; Andrews, 2018). In addition, it has been shown that fire intensity (and subsequent fire severity) increased as the rate of spread of the fire-front incremented (Viedma et al., 2015; Andrews, 2018).

Just as fire severity has myriads of ecological and management impacts, it can also be measured in many ways (Safford et al., 2008; Keeley, 2009). Field-based approaches have estimated fire severity using consumption of organic horizons, ash color, biomass loss of shrubs or trees, height of the scorch, canopy consumption and tree mortality, among other metrics (e.g. Moreno and Oechel, 1989; Pérez and Moreno, 1998; van Wagtendonk et al., 2004; Hammill and Bradstock, 2006; Fernandes et al., 2010; Welch et al., 2016). Nevertheless, the relatively high cost of these field-based approaches has led to the widespread use of remotely sensed images to analyze large landscapes for fire severity (Parks et al., 2014). Recently, higher spectral, temporal, and spatial resolution data have become available from new sensors like the Sentinel 2 MultiSpectral Instrument (MSI) (e.g., Mallinis et al., 2018). 
There is an active discussion about which of the most oftenly used spectral indices is best suitable to estimate fire severity and under what conditions (Parks et al., 2018; Harvey et al., 2019). Several studies have reported that the Normalized Burn Ratio (NBR) (NBR: [NIR-SWIR]/ [NIR + SWIR]) and its derivatives, such as the differenced Normalized Burn Ratio (dNBR), the Relative differenced Normalized Burn Ratio (RdNBR), and the Relativized Burn Ratio (RBR), appear to be the most appropriate standard spectral indices for estimating fire severity (Parks et al., 2014). However, it has also been found that in heterogeneous areas, with high presence of shrubs and grasses, dNBR can be a poor preditor of field-based fire severity measures (e.g., Allen and Sorbel, 2008; Harvey et al., 2019). The dNBR as a metric of absolute change is strongly correlated with pre-fire green biomass. Therefore, areas with low pre-fire vegetation cover (i.e., low pre-fire NBR value) will generally have low dNBR values, regardless of the degree of fire severity (Miller and Thode, 2007; Parks et al., 2014). Accordingly, when prefire vegetation is spatially variable, RdNBR and RBR may offer an improvement over dNBR. Nevertheless, there is no strong consensus regarding the strengths and weaknesses of each index, owing mainly to the variable performance of these metrics across different biophysical gradients (Cansler and McKenzie, 2012; Parks et al., 2018).

In this paper we analyze the spatial variability of fire severity in a large fire that occurred in southeastern Spain (Yeste, Albacete) in summer 2017, using three sets of explanatory variables related to (1) prefire vegetation, (2) LiDAR metrics and (3) burning conditions (fire propagation, weather and topography). A main novelty in this work is that we incorporate to our analytical framework a number of variables that rarely combined together, including field-based fire severity measures as control, fire progression maps, LiDAR, and fire-weather data at high spatial and temporal resolution. We also calculate 3 spectral indices as estimates of fire severity, derived from the NBR (i.e., dNBR, RBR and RdNBR) using Sentinel 2 MSI and Landsat 8 Operational Land Imager (OLI) images. Using this unique dataset, we asked five questions: 1) Do the various fire severity indices derived from different satellites reflect field-based fire severity equally well? 2) How prefire vegetation characteristics (including fuel models) affects fire severity? 3) Can LiDAR data help to more robustly determine the role of vegetation on fire severity? 4) How is fire severity related to burning conditions? 5) In what ways do prefire vegetation and burning conditions interact in driving fire severity?

\section{Methodology}

\subsection{The study area}

The study area was the Yeste fire (Albacete province, SE Spain), that occurred in summer 2017 (Fig. 1a). The fire started on July 27th, one day before of an incursion of warm tropical air from Africa, and was controlled on August 1st, after burning 3217 ha. Prefire weather conditions, characterized by the percentiles of the average air temperatures (a proxy for thermal stress of forest fuels) and the Drought Code (DC) of the Canadian Fire Weather System from of the previous 7 days, indicated that at the start of the fire thermal stress was approximately the 60th percentile and increased to the 95th percentile by the time of fire containment, whereas drought conditions were moderate 35th percentile before and during the fire. The Azores anticyclone with anomalous advection of hot and dry air from northern Africa was the dominat synoptic pattern during the fire. Depending on the dominant spread factor, this fire was the result of a combination of topography and wind. Under wind dominated phases, the fire spread with high intensity as both a surface fire and a passive crown fire, with spotting caused by firebrands (personal communication by the personnel of the Forestry Services of Castilla-La Mancha). Winds during the event came predominantly from the W-NW, shifting periodically to $E$-SE with sustained maximum velocities between 50 and $80 \mathrm{~km} / \mathrm{h}$ (Fig. 2a). Air temperature was very high, with maxima $38-40{ }^{\circ} \mathrm{C}$, and minima $>20^{\circ} \mathrm{C}$ (Fig. $2 \mathrm{~b}$ ).
Relative humidity was generally low $(<5 \%$, with some moister peaks near 25\%). The burned area primarily affected pine forests (i.e., Pinus pinaster Ait., Pinus halepensis Mill. and, to a lesser extent, Pinus nigra Arnold) (44\%); open Pinus halepensis woodlands with dense understory of grass and/or shrubs (40\%); and shrublands (Juniperus oxycedrus L. and Arbutus unedo L.) (16\%) (Fig. 1b).

\subsection{Spectral fire severity indices and field-based composite burn index (CBI)}

Two Sentinel 2 MSI images (10 m pixel), captured on July 18th, 2017 (prefire), and August 14th, 2017 (immediately postfire), were downloaded from the Copernicus open access hub server at the processing level L1C. Correction of the images for surface reflectivity (level L2A) (hereafter 'Sentinel 2A') was made using the Sen2Cor processing tool in SNAP 6.0 software (https://step.esa.int/main/snap-6-0released/). All bands were resampled to $10 \mathrm{~m}$ pixel resolution, using the reference band B2, and a water and cloud mask, available for each scene in SNAP 6.0, were overlaid. In addition, two Landsat 8 OLI images (30 m) from July 16th, 2017 and August 22th, 2017, corrected for radiometric, geometric and terrain distortions with LaSRC system algorithm, were obtained (https://earthexplorer.usgs.gov/). We used the Normalized Burn Ratio (NBR) to calculate the following spectral fire severity indices: $d N B R=N B R$ prefire $-N B R$ postfire, $R B R=(d N B R /$ $(N B R$ prefire +1.001$))$ and $R d N B R=(d N B R /($ square root $(a b s(N B R$ prefire (1000))) from Sentinel 2A and Landsat 8 OLI images, respectively (see Miller and Thode, 2007 and Parks et al., 2014 for further details). In addition, we calculated the ground-based Composite Burn Index (CBI) (Key and Benson, 2006) that generates a score for burn severity between zero and three (from lower to higher burn severity), based on ratings of up to 23 biophysical variables, which were divided into five sections based on forest strata level, herbs and low shrubs, tall shrubs and saplings, intermediate trees and mature, tall trees. CBI was estimated from field sampling in 57 plots $(30 \mathrm{~m}$ diameter) located in proximity to major travel routes and within areas with homogeneous fire severity levels, and related it with the spectral fire severity indices using linear and 2nd order polynomial models (Fig. 1c). Finally, to estimate the area covered by different levels of fire severity, we classified the spectral fire severity indices according to their statistical distributions into CBI classes defined following standard thresholds (Key and Benson, 2006; Fernández-Garcia et al. 2018): low-moderate ( $\leq 2)$, moderate-high $(>2$ to $\leq 2.5$ ), high $(>2.5$ to $<3.0$ ) and very high (3).

\subsection{Sets of explanatory variables}

\subsubsection{Vegetation data}

Prefire vegetation composition (i.e., dominant and codominant species) was derived from the latest National Forest Map (NFM) (1996-2007) at 1:50.000 scale (https://www.miteco.gob.es) (Fig. 1b). Prefire tree spacing and tree volume $\left(\mathrm{m}^{3} / \mathrm{ha}\right)$ were available from the 4th National Forest Inventory (NFI) (http://visores.castillalamancha. es/ginfor/\#/app) (SM Table 1 and SM Fig. 1 a-b). Finally, some biophysical variables (i.e., Leaf Area Index [LAI] and fraction of Photosynthetically Active Radiation [fPAR]) were estimated from the prefire Sentinel 2A image (July 18th 2017) using SNAP 6.0 software (https:// step.esa.int/main/snap-6-0-released/) (SM Table 1 and SM Fig. 2). LAI and fPAR were estimated using Neural Networks trained with simulated leaf optical properties and the top of canopy reflectances derived from the Radiative Transfer Models PROSPECT and the PROSPECT + SAIL, respectively.

\subsubsection{LiDAR metrics}

LiDAR data were obtained from the 2nd Spanish National LiDAR flight, carried out over the study area on 2016, and downloaded from the Spanish Geographic Institute (SGI) (http://centrodedescargas.cnig. 

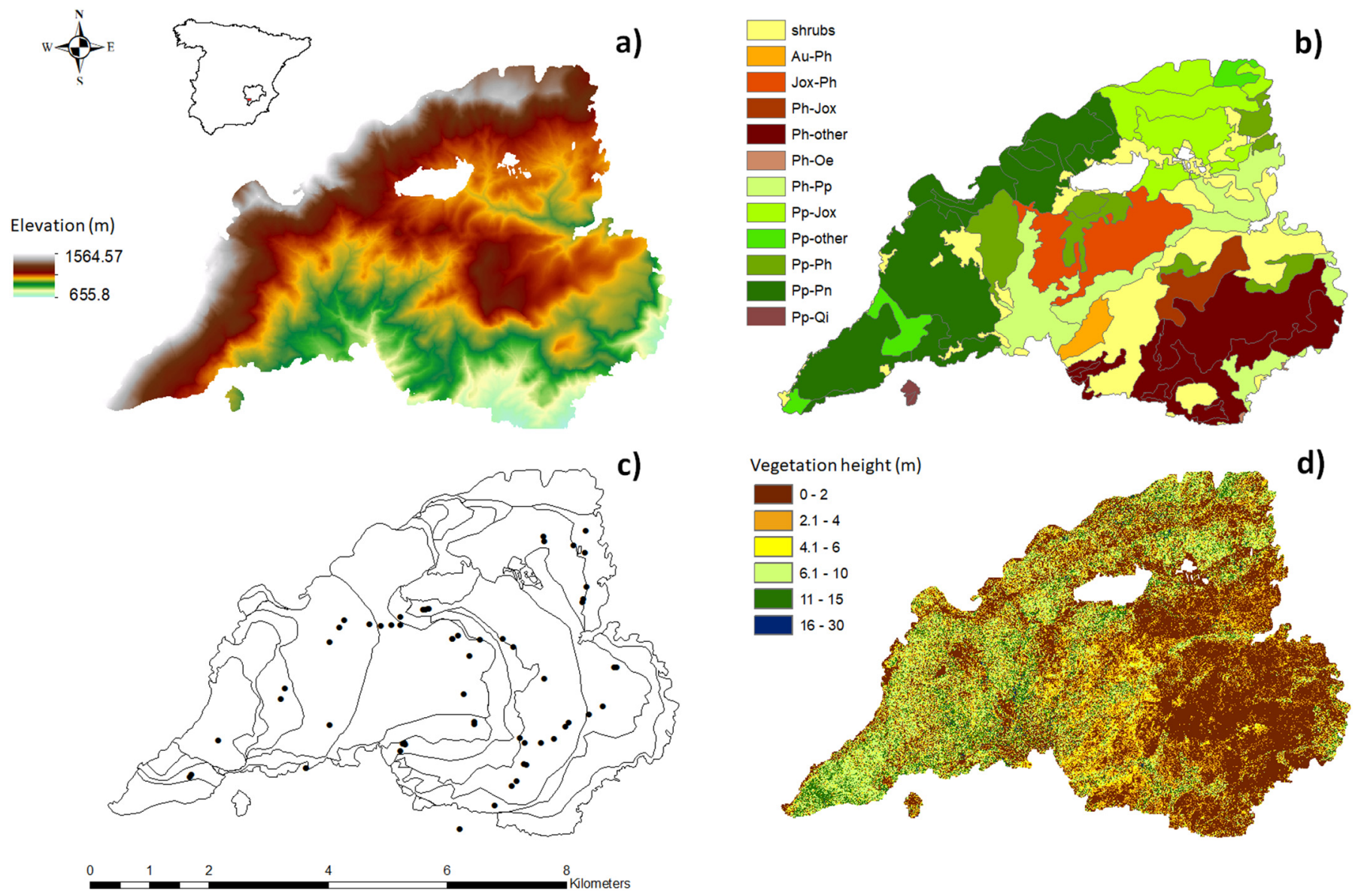

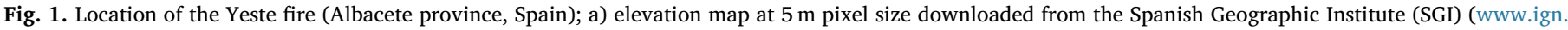

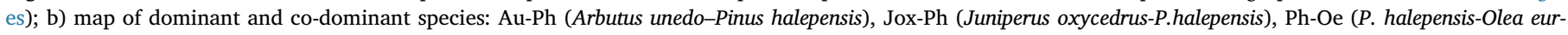

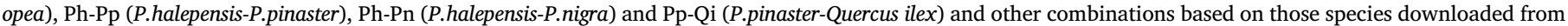

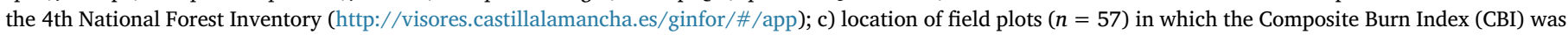

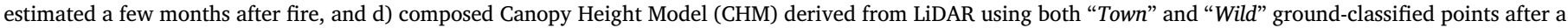
masking approach (see SM Figs. 1-2).

es/CentroDescargas/index.jsp). There were up to 4 returns per pulse, and the average point density per square meter was 1.29 for all returns, and 1.11 for last returns (available at: http://pnoa.ign.es/ especificaciones-tecnicas). LiDAR points were filtered for noise using LasTools (Rapidlasso, 2019) and CloudCompare software (http://www. cloudcompare.org/), which considerably reduced the amount of noise (Fig. 3).

After pre-processing LiDAR files, ground returns were classified using LasTools (Rapidlasso, 2019), and a sensitivity analysis was carried out using different settings, including the original classification of ground points in LAS files, as well as the settings applied by Silva et al. (2017) for assessing the accuracy of the derived Canopy Height Model (CHM) (see accompaining Methods paper). After that, we used two ground filters: a smooth one, using -town option and low spike and offset values (called 'town' hereafter), and a rough one, using -wilderness option and high spike and offset values ('wild') for normalizing the height of the points above the ground and calculating the Canopy Height Models (CHMs) (Fig. 3).

The two CHMs derived from town and wild ground-classified points showed deficiencies caused by Type I and Type II errors (SM Fig. 3), which were corrected by applying a masking approach (SM Fig. 4), resulting in a 'composed' CHM free of errors (Fig. 1d). We applied a "spike-free" algorithm (Khosravipour et al., 2016) to build the CHMs at $2 \mathrm{~m}$ pixel size using LidR package (Roussel and Auty, 2018) in R software (R Core Team, 2017). This method solves the problem of empty pixels and so called "pits". Afterwards, we detected trees and segmented their crowns from LidR package (Roussel and Auty, 2018), and computed several metrics for crown area and maximum height (mean, median, standard deviation, minimum and maximum) at $30 \mathrm{~m}$ pixel size and delineated crown contours using the raster package (Hijmans and van Etten, 2012) from R software (R Core Team, 2017) (Fig. 4 and SM Fig. 5).

Height metrics for different vegetation strata $(<2 \mathrm{~m}$ and $\geq 2 \mathrm{~m})$ were calculated at $10 \mathrm{~m}$ and $30 \mathrm{~m}$ pixel size using LasTools software (Rapidlasso, 2019) (SM Table 2). We only show results from the $30 \mathrm{~m}$ data since they are very similar to the $10 \mathrm{~m}$ data, and the $30 \mathrm{~m}$ data provided a better statistical fit. For vegetation $<2 \mathrm{~m}$, the normalized 'Town' ground points were used, whereas for vegetation $\geq 2 \mathrm{~m}$ we used the normalized 'Wild' ground points due to the Type I and Type II errors that such filters had for classifying ground points separately (SM Fig. 3). In addition, as a measure of the relative shape of the canopy ( $\geq 2 \mathrm{~m}$ ), we used the Canopy Relief Ratio (CRR) (Parker and Russ, 2004), which is defined as: [Hmean-Hmin/Hmax-Hmin], where Hmean, Hmin, and Hmax are the mean, minimum and maximum canopy heights, respectively. This ratio reflects the degree to which outer canopy surfaces are in the upper (CRR $>0.5$ ) or in the lower (CRR $<0.5$ ) portions of the height range. Then we obtained the density of different height bins below $2 \mathrm{~m}(<0.6,0.6-1,1-1.99 \mathrm{~m})$ and above $2 \mathrm{~m}(2-4,4-6,6-8$, $8-10,10-15,15-20,>20 \mathrm{~m}$ ) by dividing the points at each height range by the total number of points and scaling them to a percentage (Fig. 4). Finally, we calculated density of height bins at $0.5 \mathrm{~m}$ until $2 \mathrm{~m}$ and at $1 \mathrm{~m}$ from that value to get several diversity metrics (i.e., Simpson 

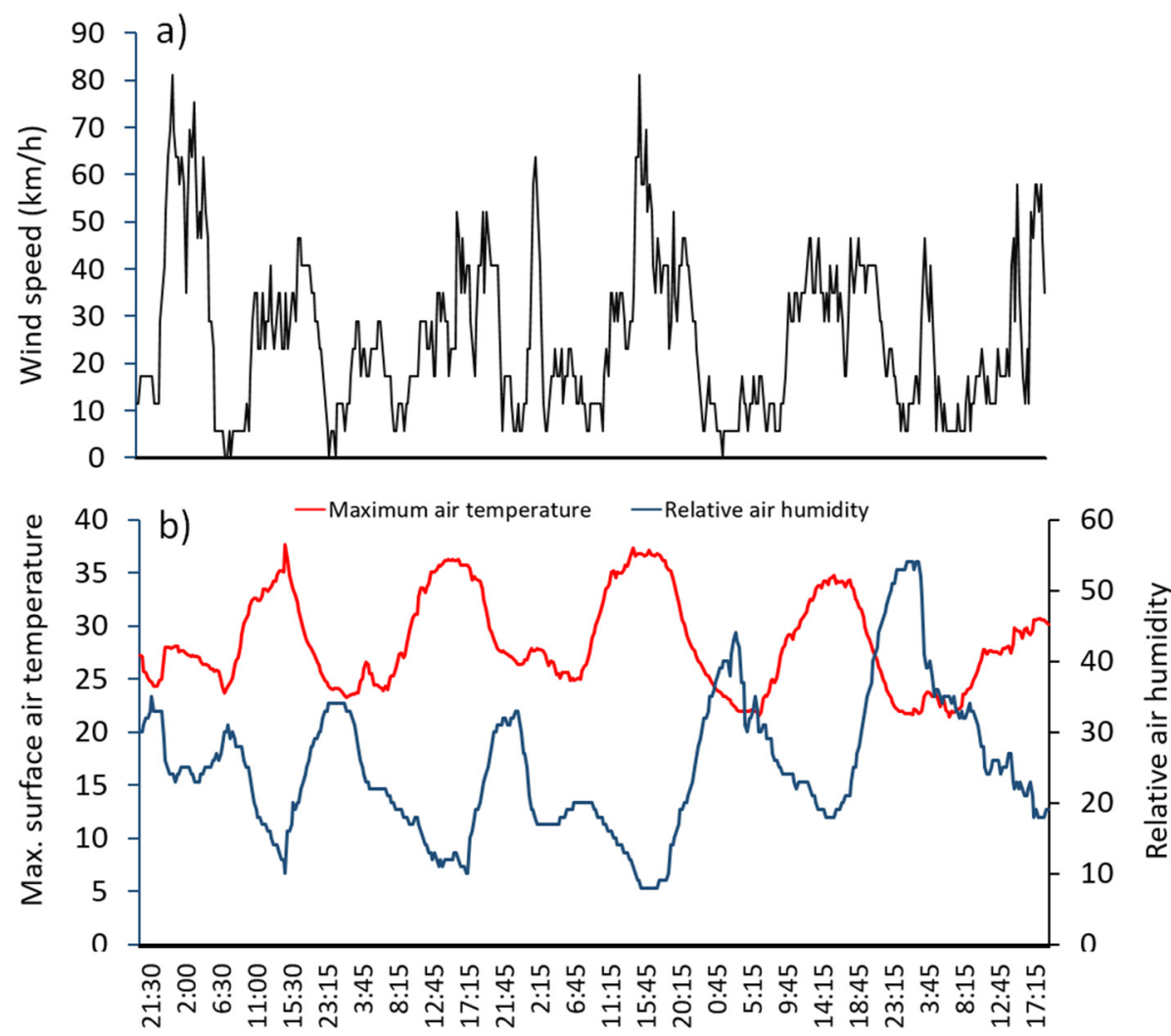

Hourly data

Fig. 2. Hourly weather data during the fire progression: a) wind speed $(\mathrm{Km} / \mathrm{h})$ and b) maximum air temperature in ${ }^{\circ} \mathrm{C}$ (left y-axis) and relative air humidity (\%) (right y-axis). The fire started on July 27th 2017 at 12;00 h, and it was controlled on August 1st at 17:15h.
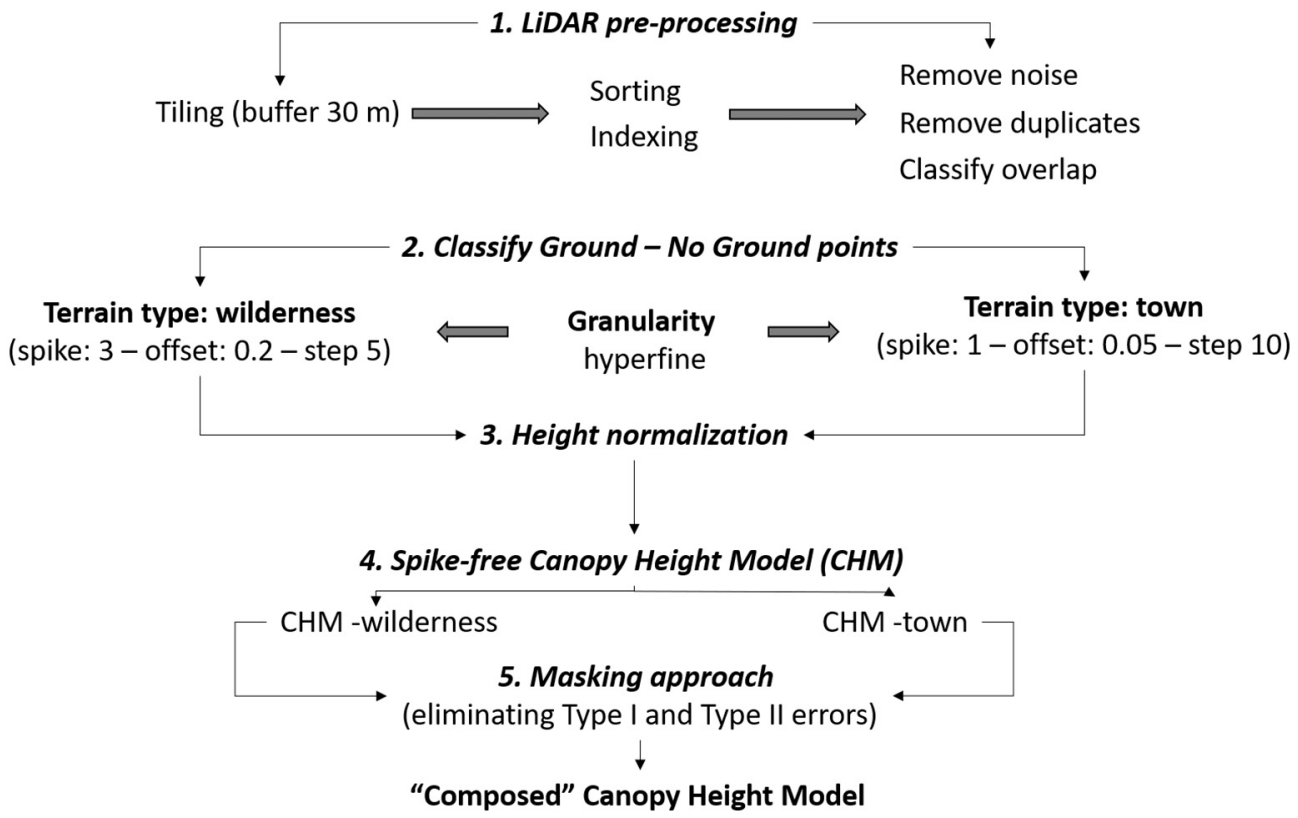

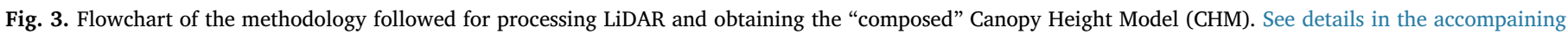
Methods paper

and Shannon diversity indices, and evenness and Berger indices for dominance indices) using Biodiversity $R$ package (Kindt and Coe, 2005) (SM Table 2 and SM Fig. 6).

Fuel models were based on the Prometheus fuel classification framework (PSP, 1999). These fuel types were defined for surface fire modelling, considering fuel height and density. The main criterion of classification is the propagation element, divided into three major groups: grass, shrubs, or ground litter (Riaño et al., 2002). Fuel types were determined using the LiDAR height metrics derived at $30 \mathrm{~m}$ and some compositional metrics (i.e., percentage covered by different height ranges $([<0.6 \mathrm{~m}, 0.6-1 \mathrm{~m}, 1-2 \mathrm{~m}, 2-4 \mathrm{~m}$ and $\geq 4 \mathrm{~m}]$ at $30 \mathrm{~m}$ pixel size) derived from the 'composed' CHM (Fig. 4). Our approach 


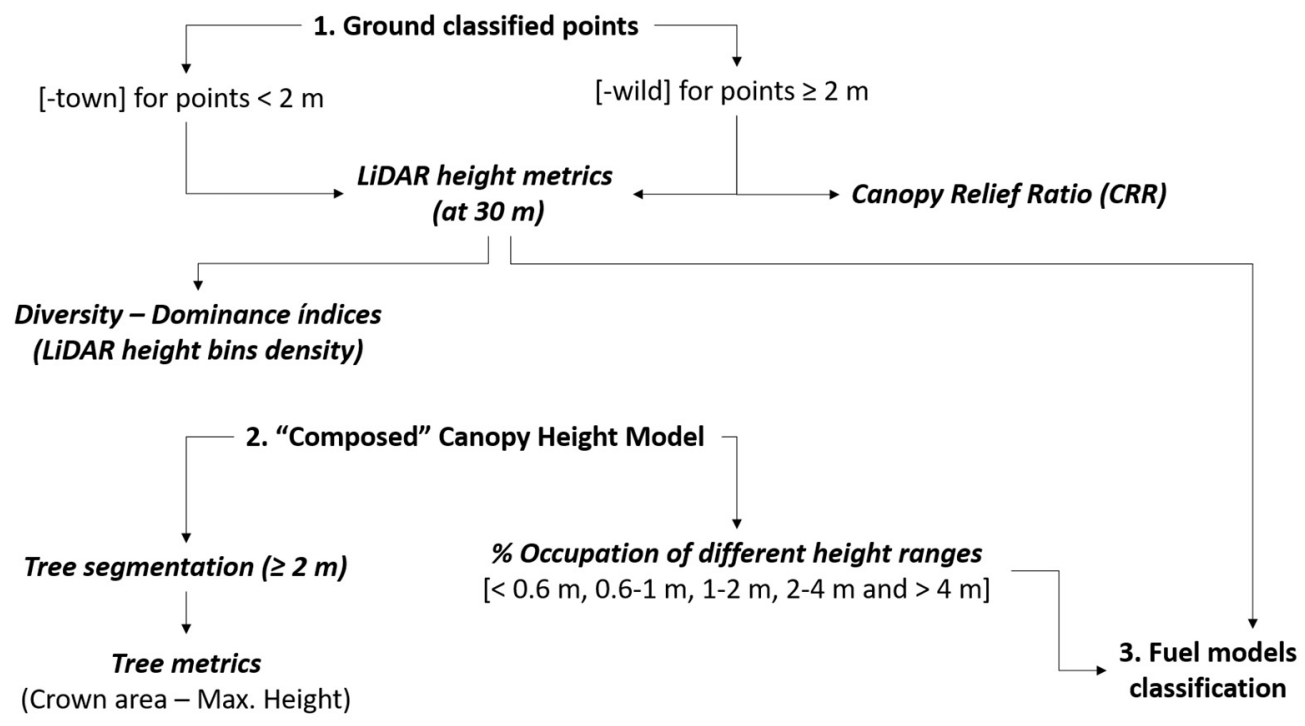

Fig. 4. Flowchart of the methodology followed for processing LiDAR and obtaining several height metrics, tree properties and the fuel models according to the cover and height thresholds established by Prometheus classification (PSP, 1999).

Table 1

Adaptation of the Prometheus fuel classification framework to the study area. Here, we have included the new fuel models $3 \mathrm{~b}$ and $8-11$.

\begin{tabular}{ll}
\hline & Fuel models (LiDAR metrics and CHM) \\
\hline $\begin{array}{l}\text { Herbs-Grasslands }(<60 \mathrm{~cm}) \\
\text { Shrublands }(<4 \mathrm{~m}) \\
\text { Small-medium }\end{array}$ & FM 1-2: $>50 \%$ of vegetation $<60 \mathrm{~cm}$ and $<10 \%$ trees \\
& FM 3a: $>50 \%$ of vegetation $60 \mathrm{~cm}-2 \mathrm{~m}$ and $<10 \%$ trees \\
Tall shrubs $/$ Small trees & FM 3b: $>60 \%$ vegetation $<2 \mathrm{~m}$ and $<10 \%$ trees \\
Forests $(\geq 4 \mathrm{~m})$ & FM 4: $>50 \%$ of vegetation $2 \mathrm{~m}-4 \mathrm{~m}$ and $<10 \%$ trees \\
Open forests & FM $8:<30 \%$ trees and $>50 \%$ shrubs with vertical continuity \\
& FM 9: $<30 \%$ trees and $>50 \%$ shrubs with no vertical continuity \\
Forest with medium density & FM 10: $>30 \%$ and $<50 \%$ trees and $>50 \%$ shrubs with vertical continuity \\
& FM 11: $>30 \%$ and $<50 \%$ trees and $>50 \%$ shrubs with no vertical continuity \\
Dense forest & FM 5: $>50 \%$ trees and $<30 \%$ shrubs \\
& FM $6:>50 \%$ and and $>30 \%$ shrubs with no vertical continuity \\
& FM 7: $>50 \%$ and and $>30 \%$ shrubs with vertical continuity
\end{tabular}

consisted on assigning established thresholds covered by each vegetation layer, and the thresholds of vertical distance to each pixel $(30 \mathrm{~m})$ using LiDAR metrics (Marino et al., 2016) (Table 1). To the Prometheus classification, we added other fuel model types that included the variability of vegetation structures found in the study area (i.e., open forests [ $<30 \%$ trees] and medium dense forest [ $>30 \%$ and $<50 \%$ trees]) (Table 1 and SM Fig. 7). Vertical continuity was measured as the difference between minimum height at the $\geq 4 \mathrm{~m}$ stratum, and the maximum height at $2-4 \mathrm{~m}$ stratum. We defined any difference $>0.5 \mathrm{~m}$ as lacking vertical continuity, otherwise there was continuity.

\subsubsection{Burning conditions}

A fire progression map (isochrones) was provided by the Forestry Services of Castilla-La Mancha as well as a map of the perimeter of a previous fire that had occurred in 1994 (Fig. 5a). Based on the isochrone map, the burned area was divided into 18 burning periods, each corresponding to the areas/polygons outlined by two consecutive positions of the fire front (isochrones). The burning periods were not of equal duration and they ranged from $1 \mathrm{~h} 30 \mathrm{~min}$ to $10 \mathrm{~h}$. From the fire progression map, we calculated two fire propagation-related variables: propagation direction (azimuth degrees) and rate of spread $\left(\mathrm{m} \mathrm{min}^{-1}\right)$ of the fire-front (Fig. 5b). We used the maximum distance between any two points across the starting and ending fire perimeters of two consecutive burning periods to determine the compass direction and rate of maximum spread of the propagating front (see Viedma et al., 2015 for further details). In addition, the weather conditions for each burning period were calculated using hourly data from an automated weather station located next to the fire. These included maximum surface air temperature $\left({ }^{\circ} \mathrm{C}\right)$ and mean air relative humidity (\%), which were assigned to every burning period (SM Table 3).

Additionaly, we used a $5 \mathrm{~m}$ resolution Digital Terrain Model (DTM) from the SGI (www.ign.es), derived from LiDAR data, to calculate aligned winds and slopes to the propagation direction of the fire-front. Hourly wind direction and wind speed data were spatially-explicit derived (from the DTM resampled at $50 \mathrm{~m}$ pixel scale to avoid spurious results) to estimate local wind changes caused by topographic variation, using the wind simulation program WindNinja (Forthofer, 2007). Using spatially explicit wind variables and fire propagation data, a measure of directional wind speed was derived ("fire-front direction vs. wind direction and speed alignment"; see Viedma et al., 2015 for further details) (SM Table 3 and Fig. 5c). Positive and high values were related to fast fire-aligned winds (i.e., wind blowing in the same direction, or close it, of the fire propagation front) and low and negative values to slower, non-aligned winds. Finally, we derived directional slope (i.e., fire-front direction-aspect alignment), based on the DTM at $5 \mathrm{~m}$ and the propagation direction of the fire-front. Negative values are given for aspects opposite to the propagating direction of the fire-front (i.e., upslope-uphill), and positive values for downslope propagation (SM 
a) Progression of the fire-front

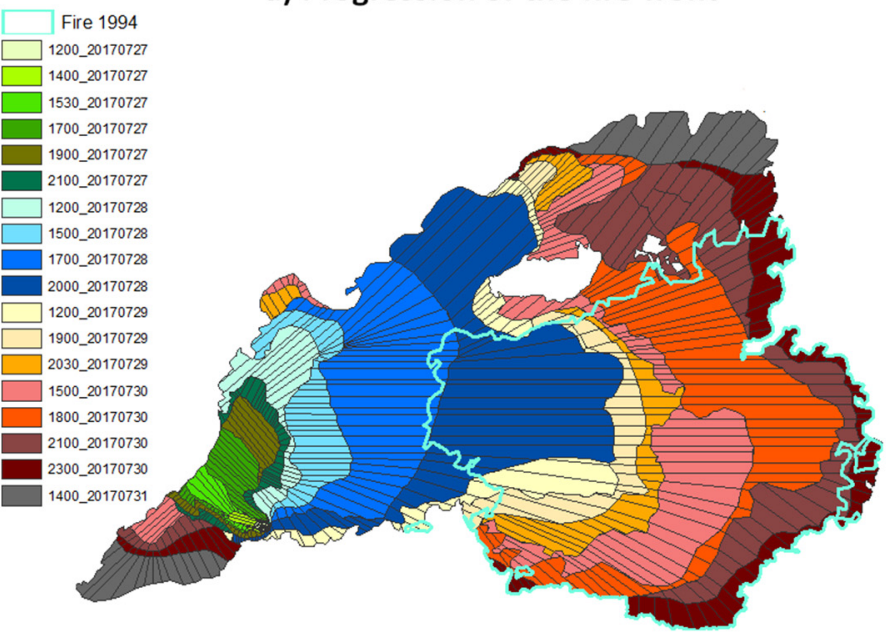

c) Directional wind speed

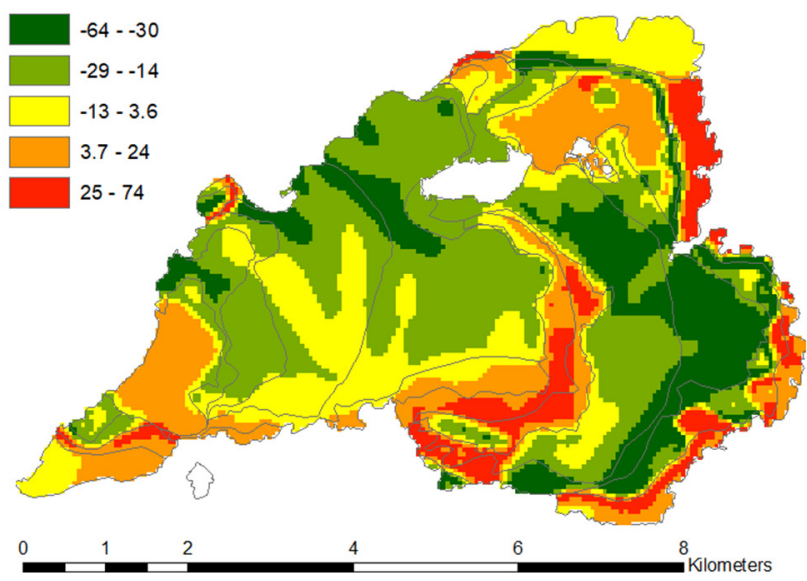

b) Rate of spread of the fire-front $\left(\mathrm{m} \mathrm{min}^{-1}\right)$

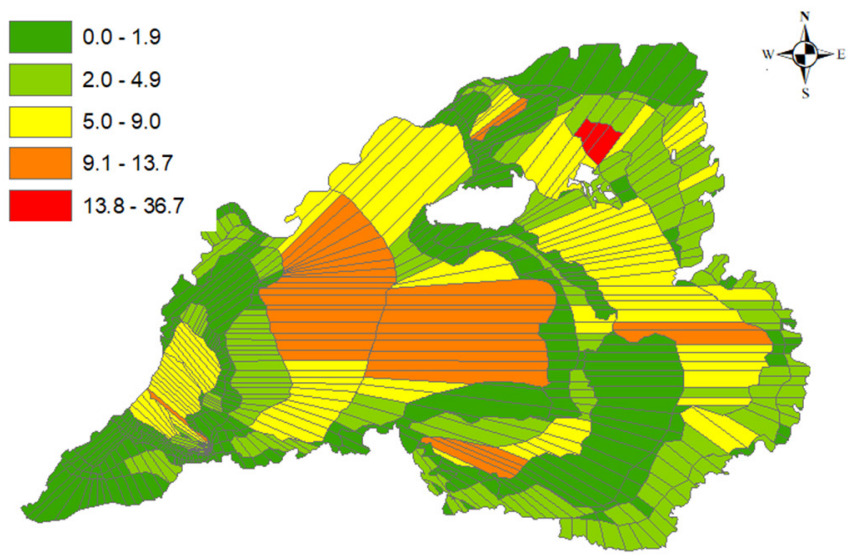

d) Directional slope

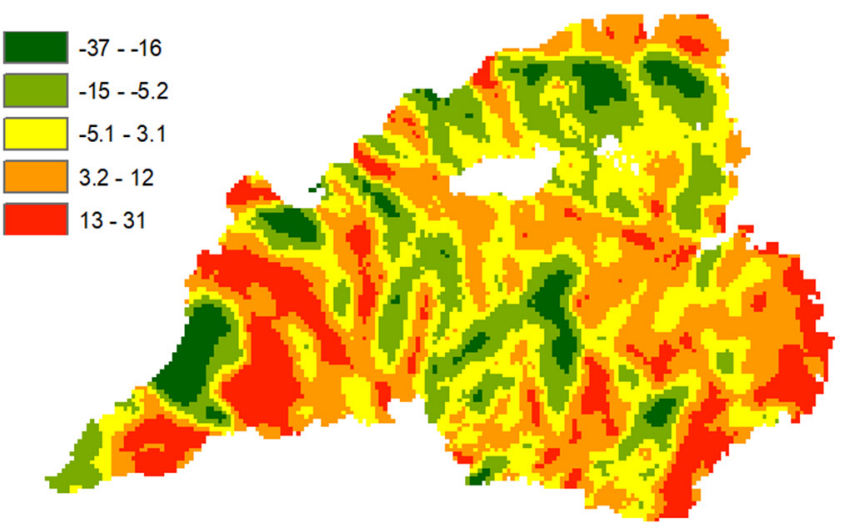

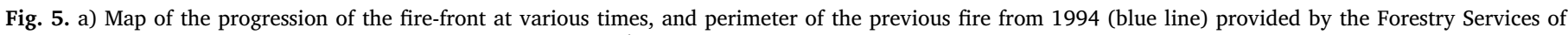

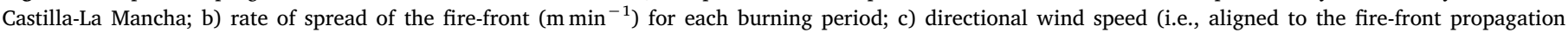

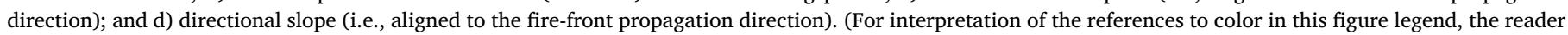
is referred to the web version of this article.)

Table 3 and Fig. 5d). We used the plugin Directional Slope (https:// plugins.qgis.org/plugins/tags/directional-slope/) in QGIS 2.18 (https://www.qgis.org/es/site/) to calculate directional slopes.

\subsection{Statistical analysis}

We determined the relationships between the spectral fire severity indices and the sets of explanatory variables (i.e., prefire vegetation, LiDAR metrics and burning conditions) (see SM Tables 1-3) using Boosted Regression Tree (BRT) models (Elith et al., 2008). Moreover, we used additional BRT models to explain the underlying factors that were behind the most important drivers of fire severity (apart from explaining fire severity) to increase our understanding about fire behaviour. The BRT approach is a nonparametric machine-learning technique that uses the technique of boosting to adaptively combine large numbers of relatively simple Regression Tree (RT) models to optimize predictive performance (Elith et al., 2008). Optimal settings for these parameters were set by examining the cross-validated residual deviance over a range of tree complexity (4-8 nodes) and learning rates (0.1, 0.01, and 0.001) (Viedma et al., 2015). The combination of the parameter settings with the lowest cross-validated residual deviance was then selected to produce the final BRT models. A variable was considered important if its relative importance for model improvement was $\geq 5 \%$, and the interaction between variables was considered significant when the Friedman's H-statistic (scaled between 0 and 1) was $\geq 0.3$ (see Viedma et al., 2015 for further details). The predictive performance of all BRT models was assessed for training $(n=800)$, stratified by the different burning periods, and independent validation $(n=220)$ at points sampled $>60 \mathrm{~m}$ apart (SM Fig. 8). Performance measures were: i) coefficient of determination $R$ to evaluate the quality of model fit for cross-validated training data (one-third of the samples were randomly assigned for the training set and the remained as the learning samples in BRT models), ii) adjusted $\mathrm{R}^{2}$ between observed and predicted data for training and validation points, iii) the autocorrelation in residuals, measured by the Moran's index, and iv) a jackknife estimator of the importance of each set of variables. The jackknife approach consisted of removing sets of predictor variables (i.e., vegetation, LiDAR metrics and burning conditions) from the full model, one at a time, as well as using only one set of variables at a time. The differences in performance measures (i.e., cross-validated R [CVR], adjusted $\mathrm{R}^{2}$ and Moran's index) between the full- and partial-models (with and without any set of variables), for training and validation data, indicated the honest contribution of each set of variables to the model (Bar Massada et al., 2012). Standard deviation of each performance measure is given between spectral severity indices. BRT models were fitted using a Gaussian data distribution of the response variable (i.e., dNBR, RBR 

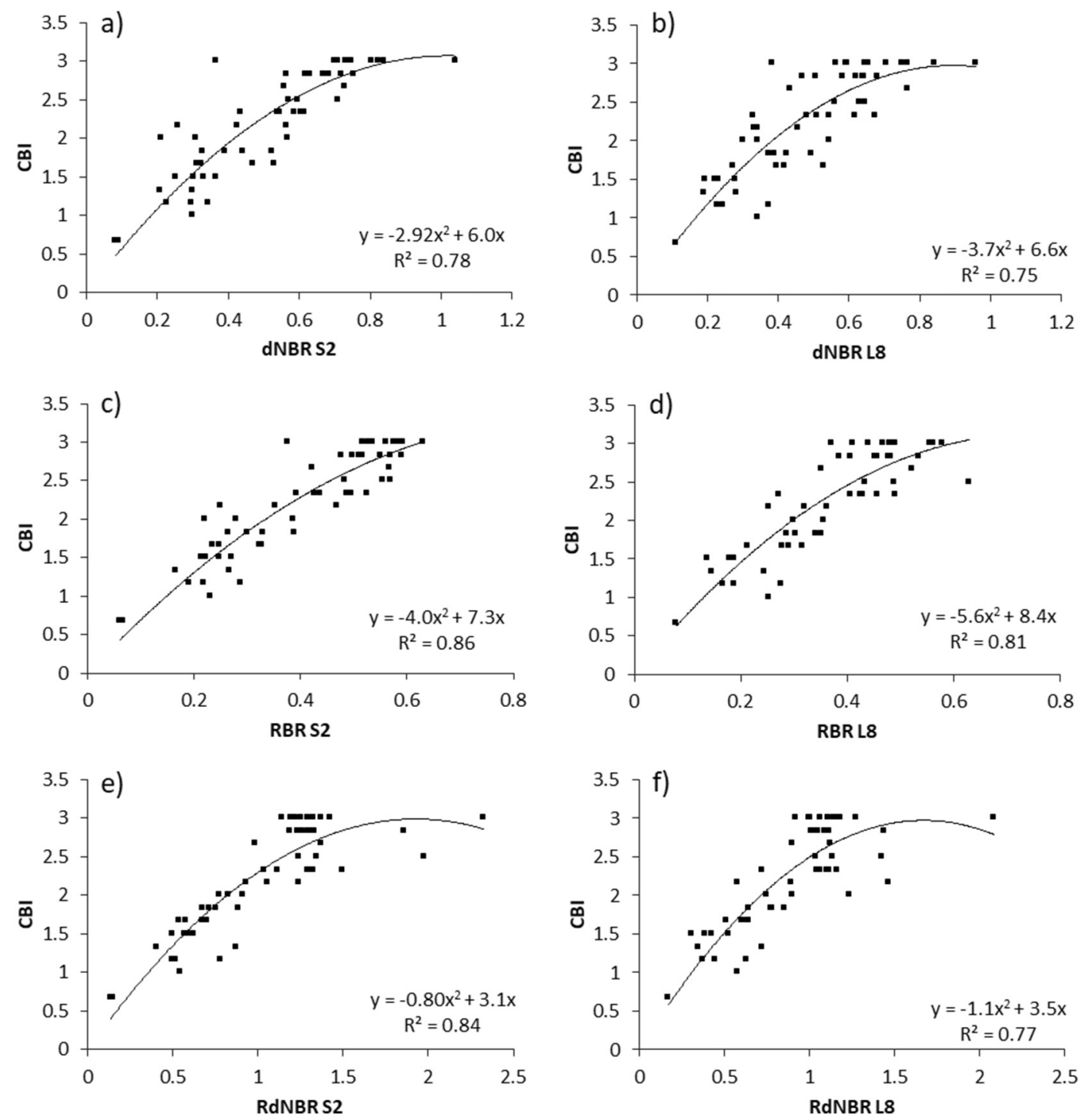

Fig. 6. 2nd order polynomial models used to fit the Composite Burn Index (CBI) to the three spectral fire severity indices used: a-b) difference Normalized Burn Ratio (dNBR) for Sentinel 2A and Landsat 8 OLI; respectively, c-d) Relative Burn Ratio (RBR) and e-f) Relative difference Burn Ratio (RdNBR).

and RdNBR severity indices for Sentinel 2A and Landsat 8 OLI) by applying the $g b m$ package (Ridgeway, 2007) and R code provided by Elith et al. (2008).

\section{Results}

\subsection{Spectral fire severity indices vs ground-based composite burn index (CBI)}

The CBI fitted RBR (linear models $\left[\mathrm{R}^{2}=0.79\right.$ and 0.72$]$, and 2nd order polynomial models $\left[\mathrm{R}^{2}=0.86\right.$ and 0.81$]$ ) better than dNBR (linear models $\left[R^{2}=0.63\right.$ and 0.56$]$, 2nd order polynomial $\left[R^{2}=0.78\right.$ and 0.75$]$ ) and RdNBR (linear models $\left[\mathrm{R}^{2}=0.56-0.51\right]$, 2nd order polynomial $\left[\mathrm{R}^{2}=0.84\right.$ and 0.77$]$ ), for Sentinel $2 \mathrm{~A}$ and Landsat 8 OLI, respectively (Fig. 6).

Concerning the area supporting different levels of fire severity, CBI classification indicated that the low and moderate fire severity classes were slightly different but non-significantly in the median values of the spectral fire severity indices, the same was true for the high and very high classes (SM Fig. 9). Grouping the four CBI classes into two $(\leq 2.5$ and $>2.5$ ), all spectral fire severity indices were significantly different, especially those derived from Sentinel 2A (SM Fig. 10). This classification produced a similar spatial pattern of fire severity among indices, and a more comparable statistical distribution than standard thresholds (SM Fig. 11). Overall, RdNBR produced a higher proportion of area burned with high fire severity (35\%) than dNBR (23\%) and RBR (17\%) (Fig. 7).

\subsection{Fire severity explanatory models}

The full BRT models based on all sets of variables (i.e., prefire vegetation, LiDAR metrics and burning conditions) showed high explanatory power (mean cross-validated regression coefficient [CVR]: $76 \% \pm 0.05 ;$ mean adjusted $\mathrm{R}^{2} \quad\left[\right.$ Adj. $\mathrm{R}^{2}$ ]: $86 \% \pm 0.04$ and $68 \% \pm 0.05$, for training and validation data, respectively, and Moran's index $0.14 \pm 0.02$ ). Deviations refer to the three spectral indices for the two satellites ( $n=6$ models) (Table 2).

Fire severity increased greatly in areas with medium-high LAI values (c.a. 1.5) for dNBR and RBR, and in areas with low fPAR values (c.a. 0.2) for RdNBR (Fig. 8 and Table 2). For all spectral indices and both satellites, the vegetation types which burned with highest fire severity were scattered trees of Pinus halepensis with shrubs (i.e., Jox-Ph and $\mathrm{Ph}-\mathrm{Jox}$ ), followed by mixed forests of pines (i.e., $\mathrm{Ph}-\mathrm{Pp}$ and $\mathrm{Pp}-\mathrm{Ph}$ ) and treeless shrublands; forest stands dominated by Pinus pinaster and 

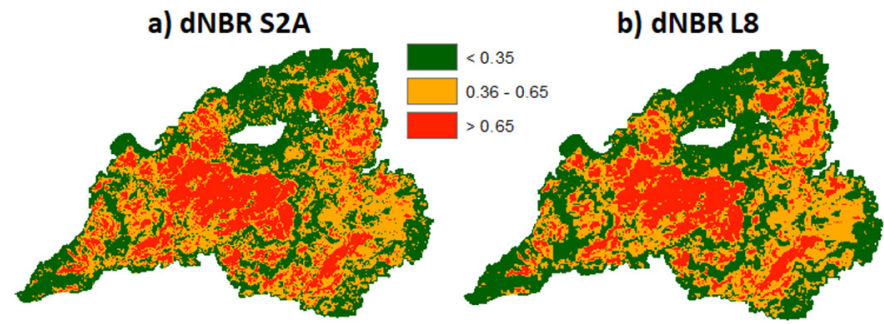

e) RdNBR S2A

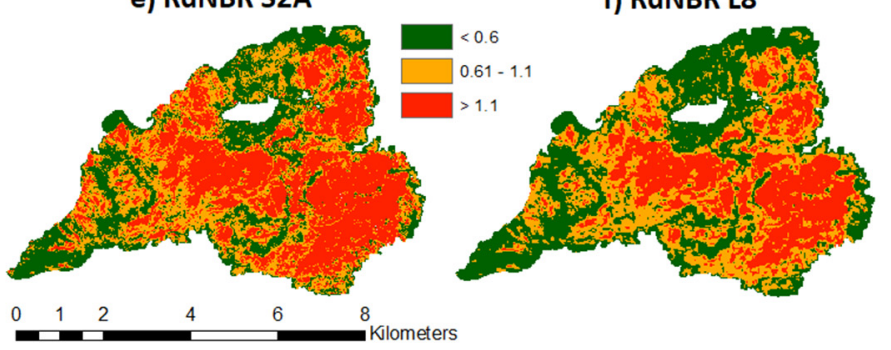

c) RBR S2A
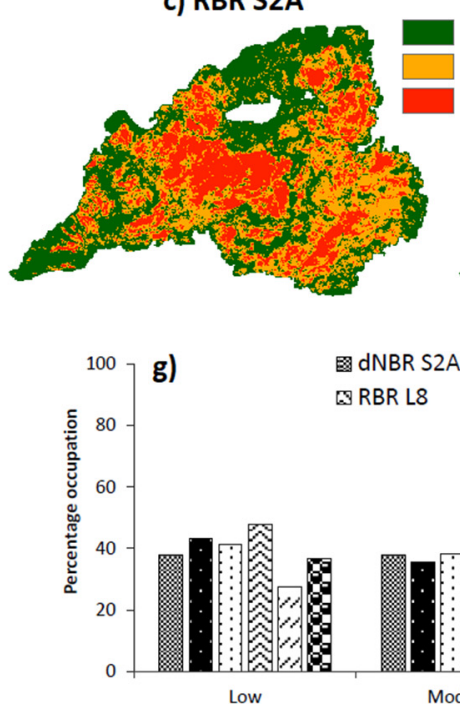

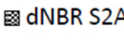

Q $\mathrm{RBR}$ L8

- dNBR l8

๑RdNBR S2A

$\square$ RBR S2A

RdNBR L8
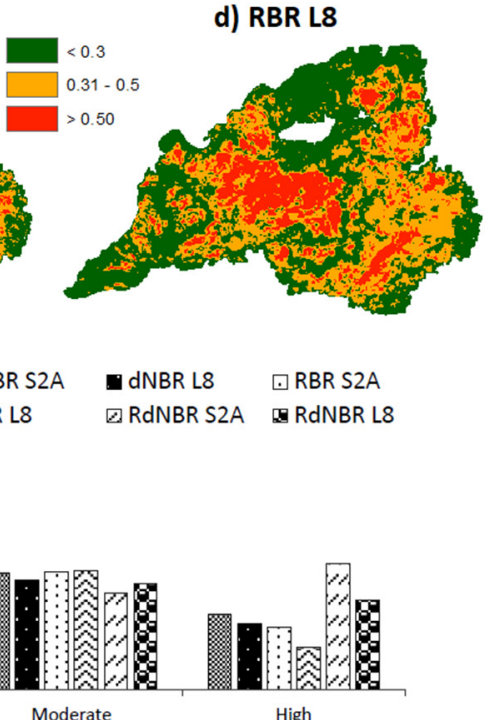

Fig. 7. Maps of fire severity classes applying a customized classification after modelling CBI with spectral fire severity indices: a) dNBR from Sentinel 2 MSI; b) dNBR from Landsat 8 OLI; c) RBR from Sentinel 2 MSI; d) RBR from Landsat 8 OLI; e) RdNBR from Sentinel 2 MSI, f) RdNBR from Landsat 8 OLI and g) percentage of occupation of the fire severity classes for each spectral index.

Pinus nigra tended to support lower fire severity (Fig. 8 and Table 2). Structurally speaking, heterogeneous stands (i.e., medium-high evenness of height bins), dominated by small-medium trees (maximum height $\geq 2 \mathrm{~m}$ below $5 \mathrm{~m}$ and trees with small crown area), with a high proportion of homogeneous tall shrubs (high density of LiDAR points between 1 and $2 \mathrm{~m}$ with a $\mathrm{P}_{90}<2 \mathrm{~m}$ greater $1.5 \mathrm{~m}$ and homogenous intensity values) burned with high fire severity. Furthermore, stands that also included a high proportion of medium shrubs $(60 \mathrm{~cm}$ to $1 \mathrm{~m})$ were severely affected by fire, mainly according to RdNBR (Fig. 8 and Table 2). Concerning fuel models, they were relevant only for explaining fire severity derived from RdNBR Landsat 8 (in full and partial BRT models), being hidden by prefire vegetation and LiDAR metrics in the case of the other spectral fire severity indices. We found that medium shrubs (FM 3), tall shrubs and/or small trees (FM 4), and open forests with shrub understory (FM 8) had high density of points between 1 and $2 \mathrm{~m}$ and low values of Hmax $\geq 2 \mathrm{~m}$, crown area and LAI; all of these properties were linked to high fire severity (Table 2 and SM Fig. 12).

Regarding burning conditions, and for all spectral indices and both satellites, higher fire severity values were found where the rate of spread of the fire-front was high (c.a. $15 \mathrm{~m} \mathrm{~min}^{-1}$, which was above the 3rd quartile), fire spread upslope (high and negative directional slopes), and when high winds blew windward and also leeward to the fire-front (especially for the RdNBR). Fire severity was also high under high maximum temperature $\left(>35^{\circ} \mathrm{C}\right.$ ) (Fig. 8 and Table 2). Recent fire history (i.e., areas burned or not in 1994) played a minor role in full models, mainly because it was hidden by other variables related to vegetation composition and structure. When only variables related to

Table 2

Native variable importance (in percentage) derived from full Boosted Regression Trees (BRT) based on prefire vegetation, LiDAR metrics and burning conditions for explaining different spectral fire severity indices. Explanatory variables (in bold) were those present in the full BRT models of all fire severity indices. Explanatory variables (in italics) showed relative importance $<5 \%$ in the full BRT models but overpassed that thresholds in partial BRT models (jaccknife approach). Explanatory variables with a relative importance $<5 \%$ in the full BRT models are not shown.

\begin{tabular}{|c|c|c|c|c|c|c|}
\hline Full models & dNBR-S2 & dNBR-L8 & RBR-S2 & RBR-L8 & RdNBR-S2 & RdNBR-L8 \\
\hline LAI/fPAR & 27.52 & 13.28 & 15.66 & 9.42 & 11.37 & 5.66 \\
\hline Dominant species & 4.85 & 6.01 & 5.65 & 7.42 & 7.69 & 15.91 \\
\hline Tree volume (vcc) & 3.78 & 3.06 & 3.93 & 3.28 & 3.39 & 3.69 \\
\hline Tree spacing $(s)$ & & & & & & 2.52 \\
\hline Intensity $\mathrm{sd}<2 \mathrm{~m}$ & 4.88 & 5.00 & 5.77 & 7.01 & 9.06 & 9.97 \\
\hline $\operatorname{Hmax} \geq 2 \mathrm{~m}$ & 5.34 & 3.49 & 6.41 & 4.49 & 11.27 & 8.22 \\
\hline Density points $1-2 \mathrm{~m}$ & 8.72 & 11.51 & 14.62 & 14.17 & & \\
\hline Evenness wilderness & 9.12 & 11.31 & 4.71 & 4.45 & & \\
\hline Median crown area & & 2.35 & 3.28 & 3.20 & 3.88 & 3.10 \\
\hline$P_{90}<2 m$ & & & & & 4.24 & 2.90 \\
\hline Vegetation cover $60 \mathrm{~cm}-1 \mathrm{~m}(\mathrm{CHM})$ & & & & & 4.36 & \\
\hline Vegetation cover $>4 \mathrm{~m}(\mathrm{CHM})$ & & & & & 12.79 & \\
\hline Fuel models & & & & & & 5.12 \\
\hline Rate of spread of the fire-front & 18.65 & 27.70 & 17.85 & 22.04 & 9.11 & 13.75 \\
\hline Max. surface air temperature & 7.57 & 6.69 & 9.77 & 9.18 & 8.70 & 12.48 \\
\hline Directional wind speed & 4.23 & 4.12 & 5.93 & 5.84 & 8.76 & 7.16 \\
\hline Directional slope & 5.35 & 5.48 & 6.43 & 6.80 & 5.37 & 5.56 \\
\hline Relative air humidity & & & & & & 4.00 \\
\hline Cross validated regression coefficient (CVR) & 0.79 & 0.81 & 0.74 & 0.78 & 0.68 & 0.76 \\
\hline Adjusted $\mathrm{R}^{2}$ Predicted vs Observed (Training) & 0.85 & 0.90 & 0.81 & 0.92 & 0.85 & 0.83 \\
\hline Adjusted $\mathrm{R}^{2}$ Predicted vs Observed (Validation) & 0.72 & 0.68 & 0.71 & 0.71 & 0.63 & 0.60 \\
\hline Residuals autocorrelation (Moran's Index) & 0.14 & 0.13 & 0.15 & 0.13 & 0.11 & 0.16 \\
\hline
\end{tabular}



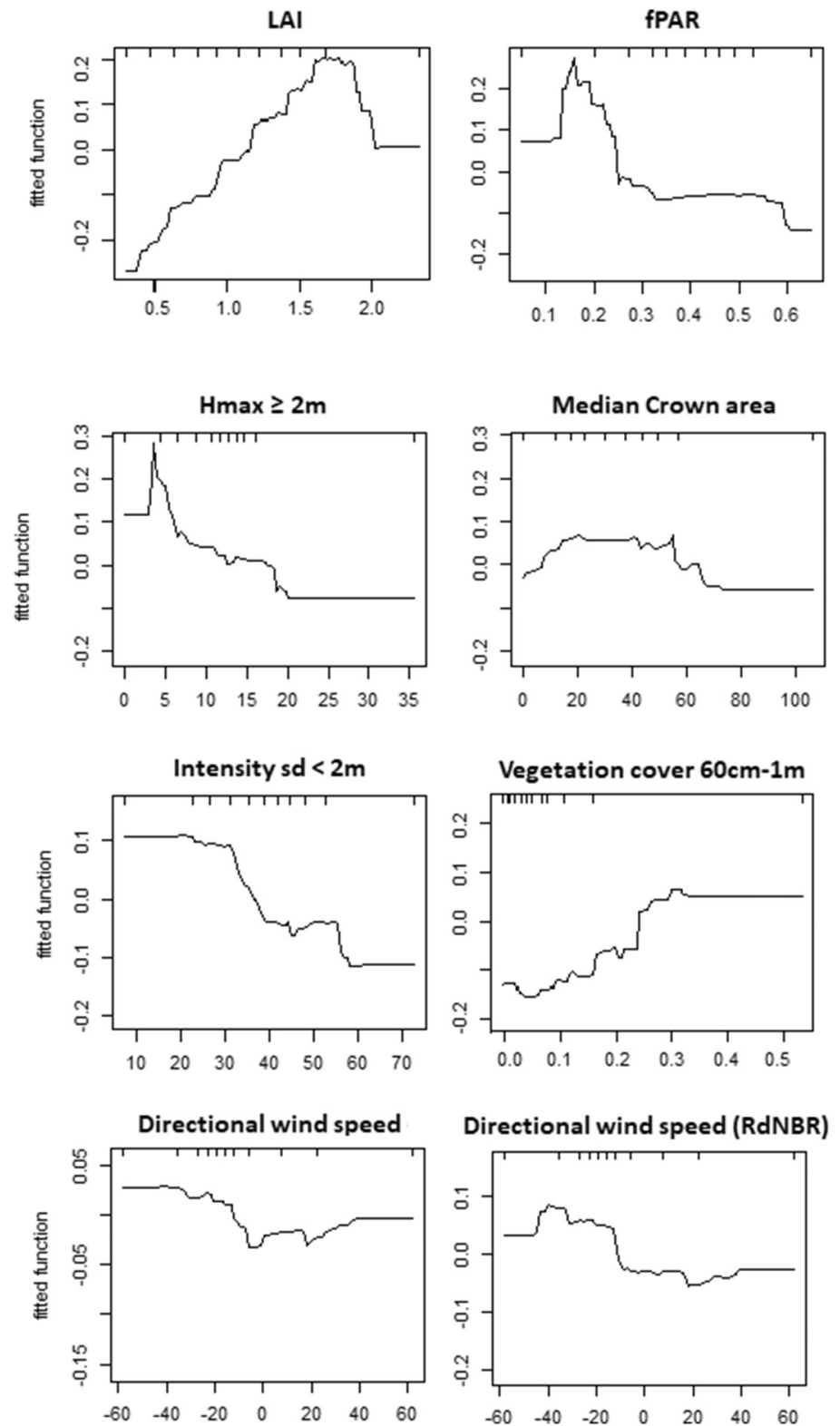

Directional wind speed (RdNBR)

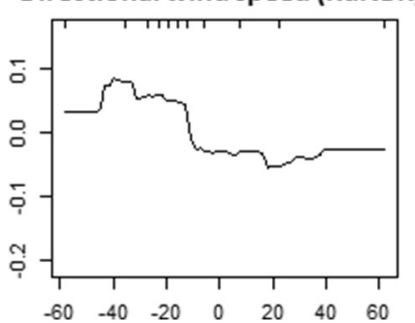

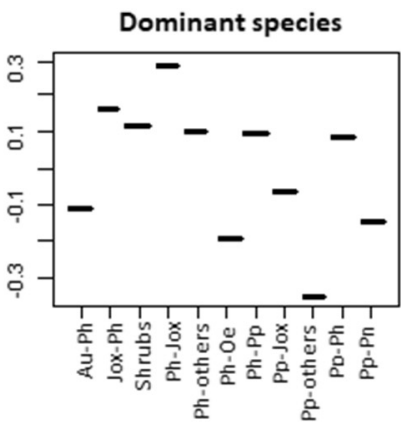
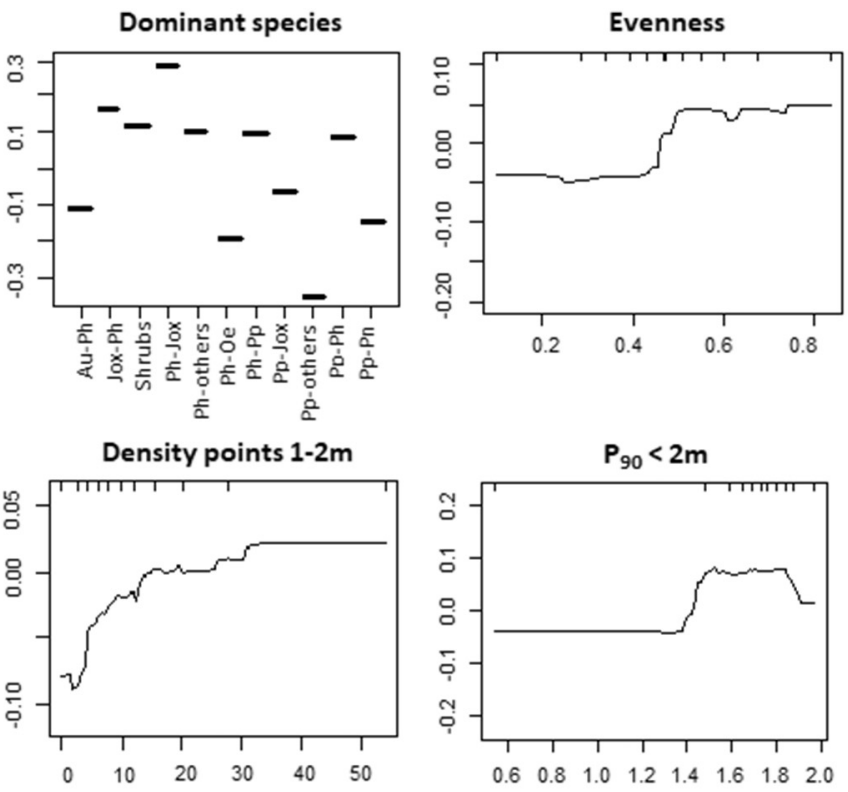

Rate of Spread of the fire-front
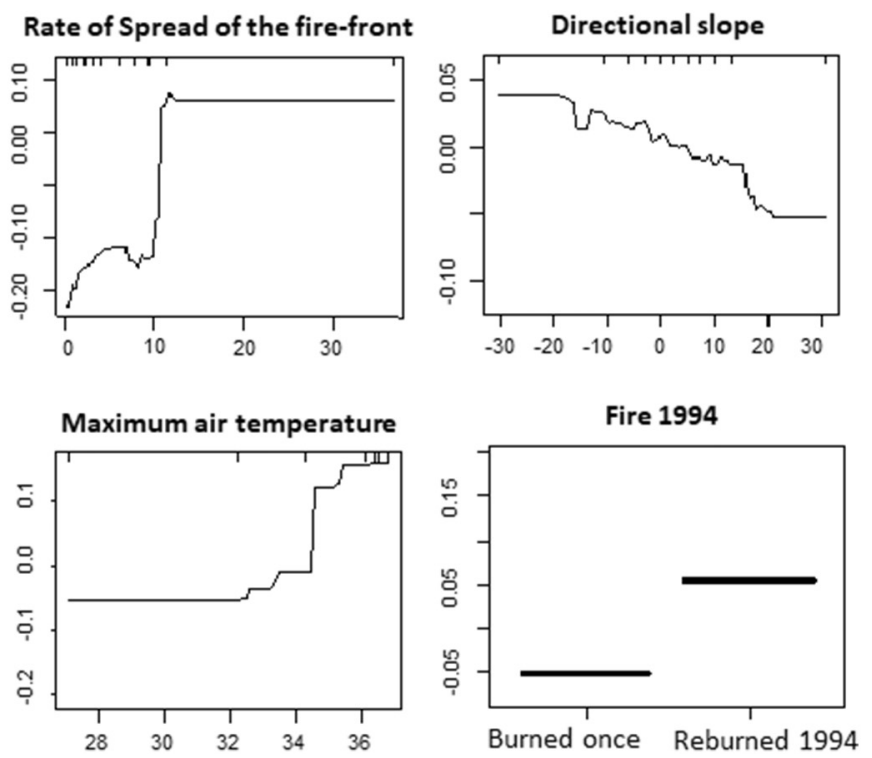

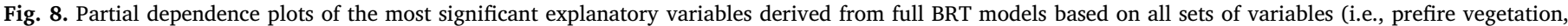
LiDAR metrics and burning conditions). The $y$-axis represents the $\mathrm{z}$ score of the spectral fire severity index and the $\mathrm{x}$-axis the original explanatory variables.

burning conditions were included in the BRT models, reburning was a significant predictor of all indices. When the set of prefire vegetation variables were included alone in BRT models, reburning was significant for RBR and RdNBR, but when considering only LiDAR variables, reburning was significant only for RdNBR. Nevertheless, reburned areas showed higher fire severity than areas not burned prior to the current fire (SM Fig. 13), having a high density of points between 1 and $2 \mathrm{~m}$ and low values of Hmax $\geq 2 \mathrm{~m}$, crown area and LAI; all of these properties were linked to high fire severity (SM Fig. 14).

According to the native variable importance derived from BRT models, the average contribution of burning conditions to the full BRT models was $39.7 \% \pm 4.9$, the average contribution of LiDAR metrics was $28.7 \% \pm 5.4$ and the contribution of prefire vegetation was $21.7 \% \pm 5.5$ (Fig. 9). There were significant differences between the contribution of burning conditions and prefire vegetation, but there were not significant differences between satellites, nor among spectral fire severity indices (Fig. 9). The single variables that most contributed to the full BRT models were rate of spread of the fire-front $(18.2 \% \pm 6.4)$, LAI-fPAR $(13.8 \% \pm 7.5)$ and density of points at
$1-2 \mathrm{~m}(12.2 \% \pm 2.7)$

Based on the jaccknife approach, variables related to burning conditions were the strongest predictors of fire severity, being slightly better (mainly in the Adj. $\mathrm{R}^{2}[56 \% \pm 0.06]$ for validation data and Moran's index $[0.24 \pm 0.03]$ ) than prefire vegetation and LiDAR metrics alone (Fig. 10). BRT models including only prefire vegetation or LiDAR metrics explained less variance (Adj. $\mathrm{R}^{2}: 45 \% \pm 0.05$ and $35 \% \pm 0.03$ for training and validation data; respectively), and there were not significant differences between them in any performance measure (Fig. 10). In addition, models including vegetation or LiDAR data plus burning conditions produced significantly higher fitting (Adj. $\mathrm{R}^{2}: 71 \% \pm 0.04$ and $61 \% \pm 0.02$ for training and validation data; respectively) than models that did not include burning conditions (i.e., models with vegetation plus LiDAR data) for all performance measures (Fig. 10). Finally, there were not significant differences between satellites neither among fire severity indices in any measure of models' performance (not shown).

Moreover, there were significant interactions among the best predictor variables, especially for $\mathrm{dNBR}$ and RdNBR (SM Table 4). 
Vegetation 圈 Lidar 四 Fire

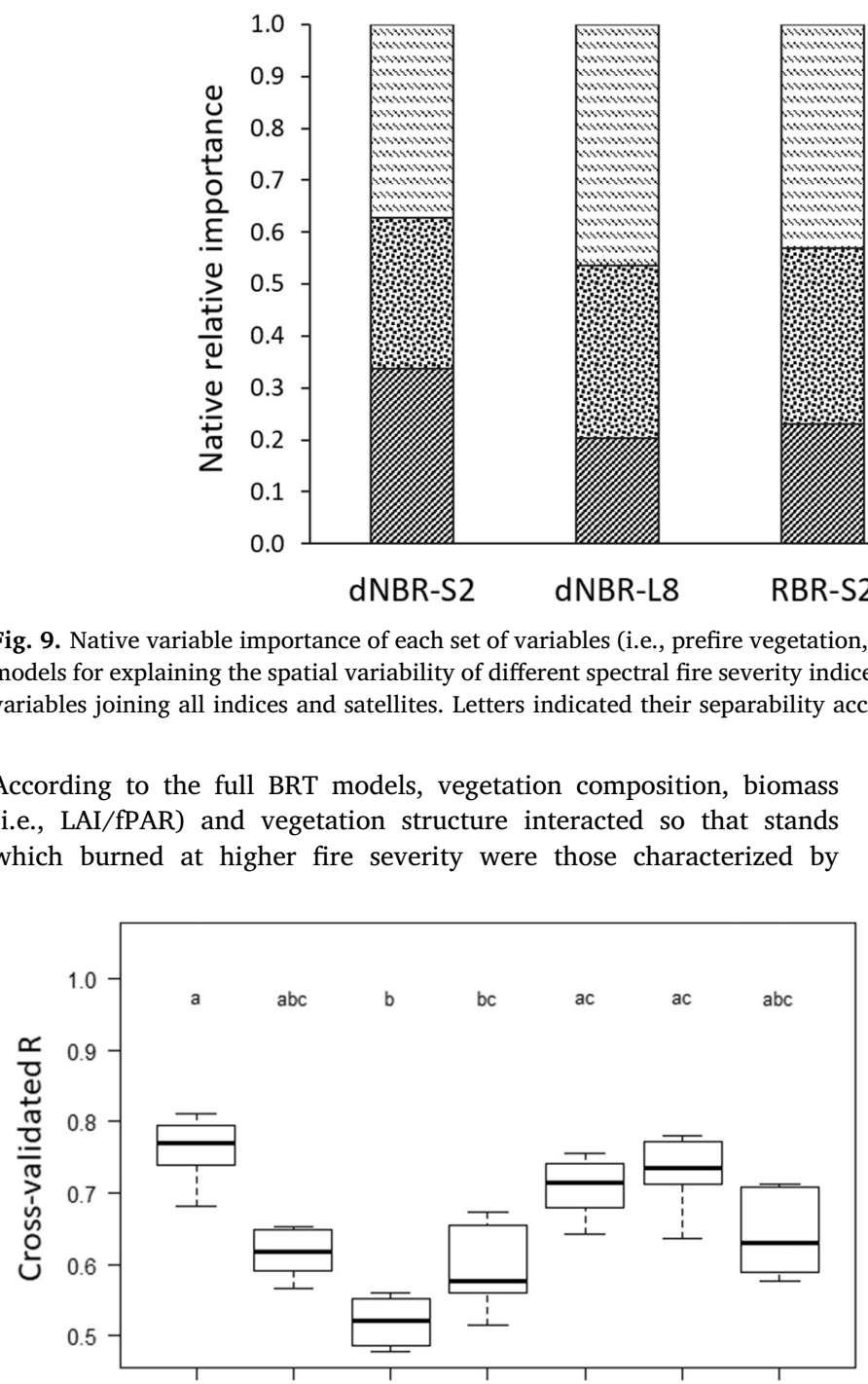

(i.e., LAI/fPAR) and vegetation structure interacted so that stands which burned at higher fire severity were those characterized by

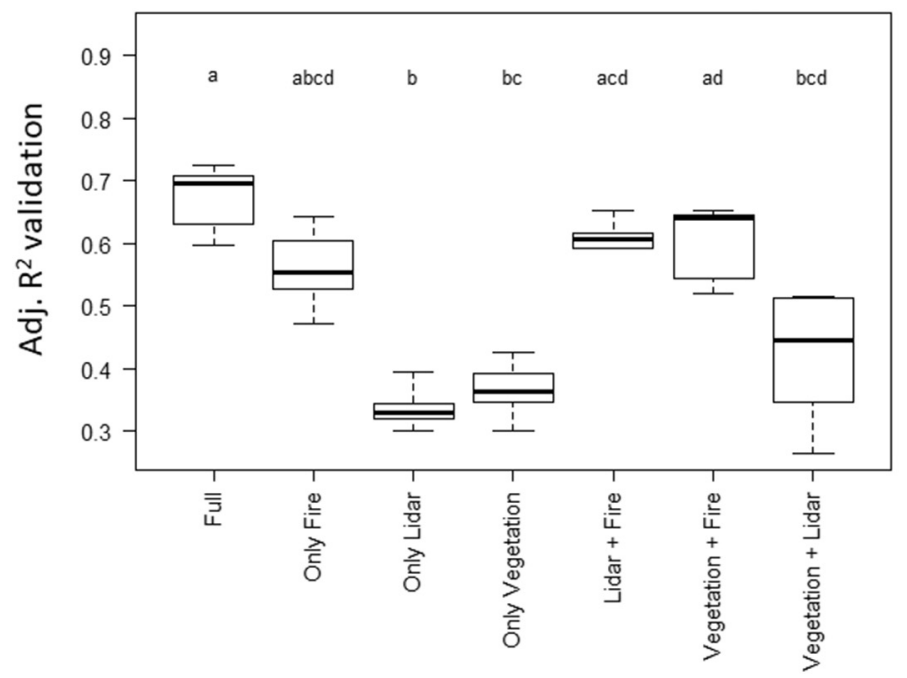

Fig. 10. Box-plots of main performance measures derived from BRT models joining all indices and satellites. From upper left to right bottom: cross-validated R, Adj. $\mathrm{R}^{2}$ for training and validation data, and autocorrelation in residuals (Moran's index). Letters shown significant differences using the Dunn Test (non-parametric post hoc test).
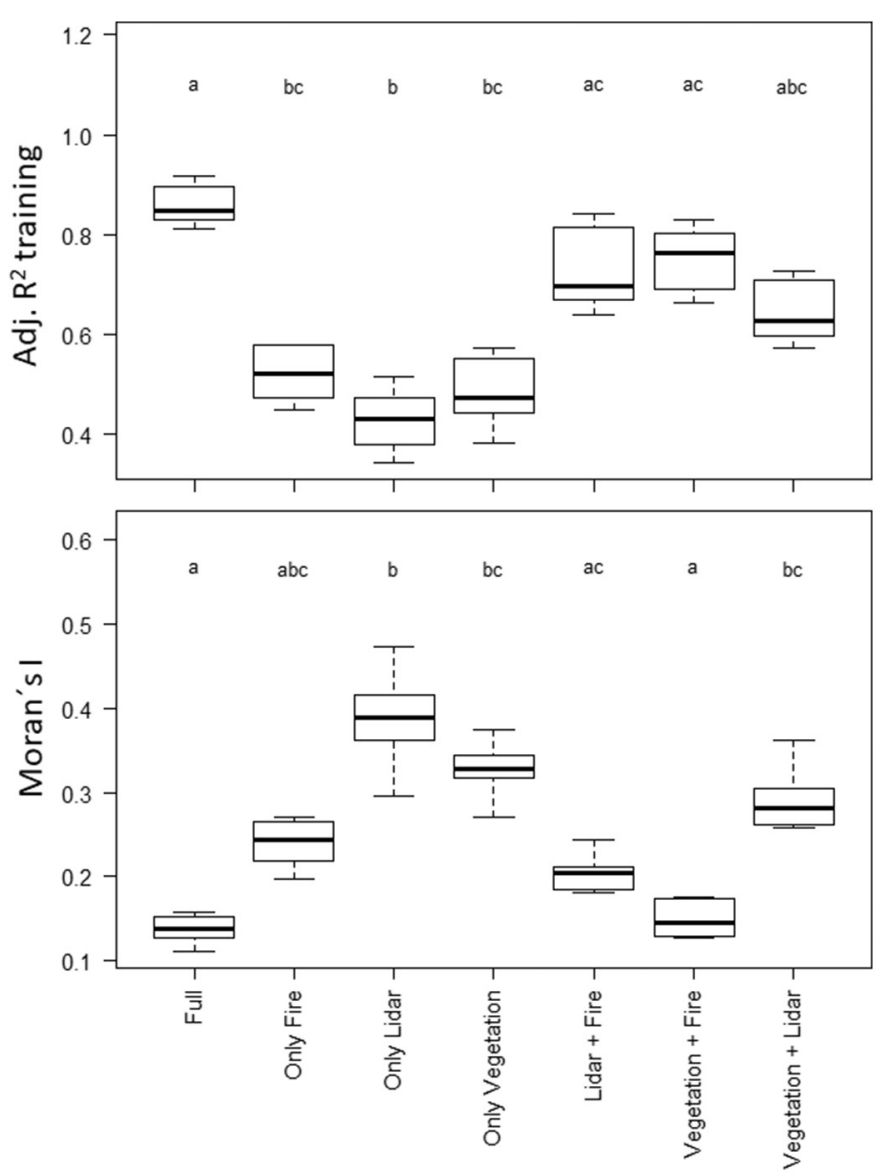

medium-high LAI or low fPAR (depending on the spectral fire severity index); small trees of Pinus halepensis and open-canopy stands with high and homogeneous understory cover (SM Table 4 and Fig. 11). 

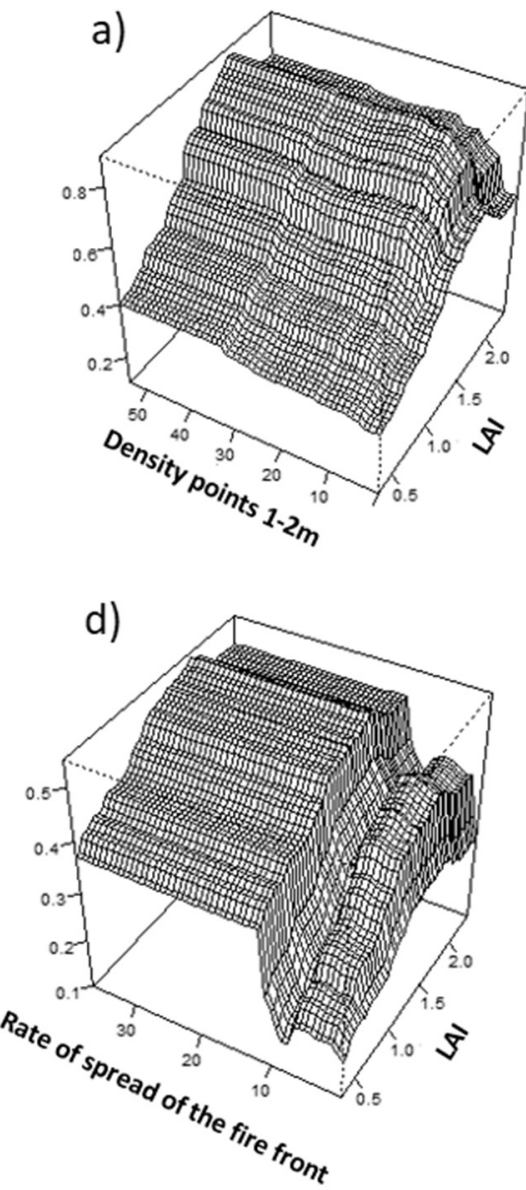
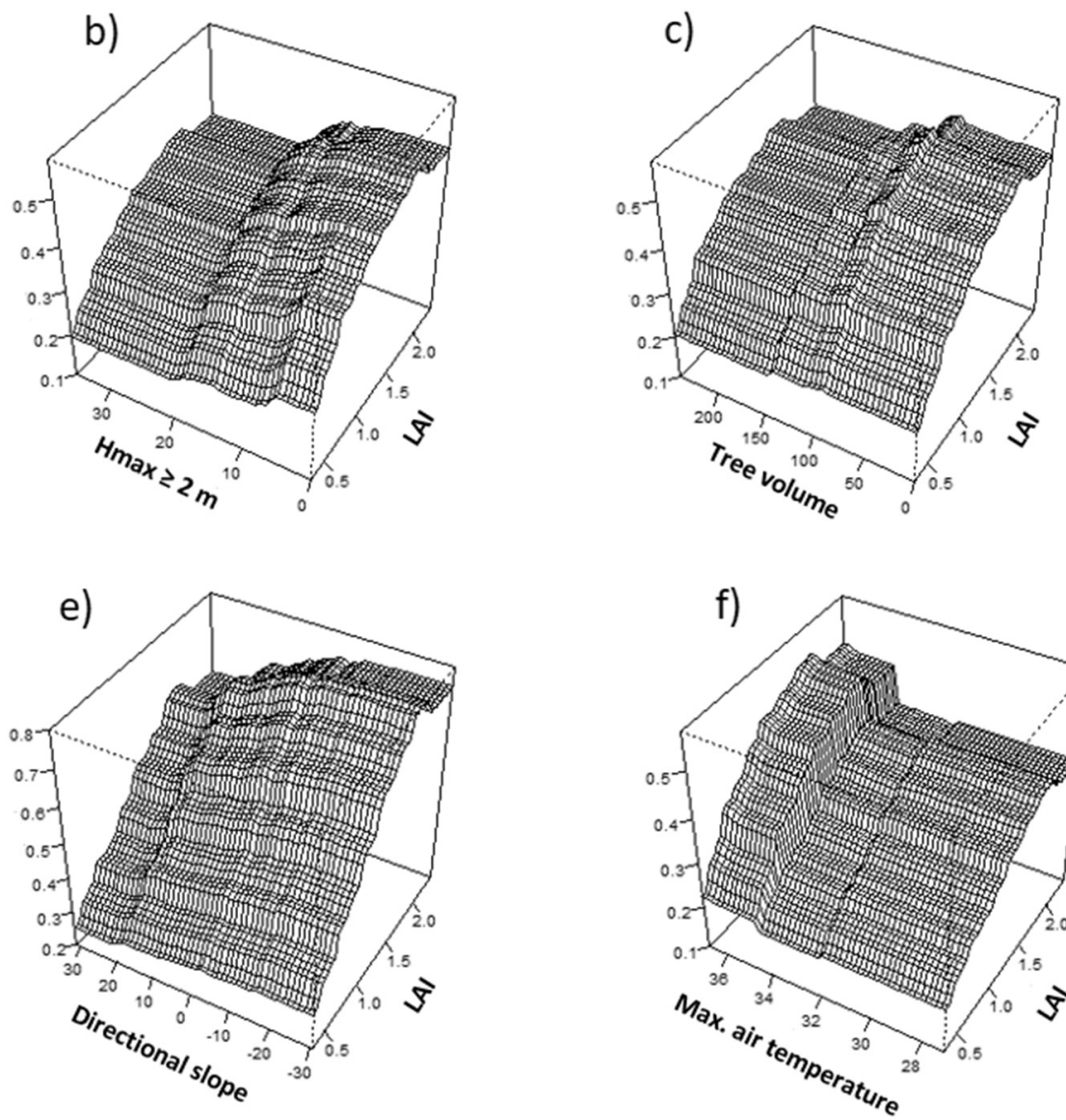

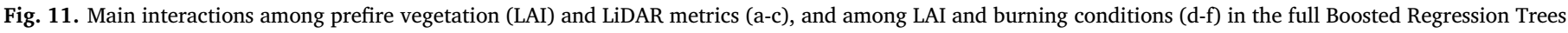

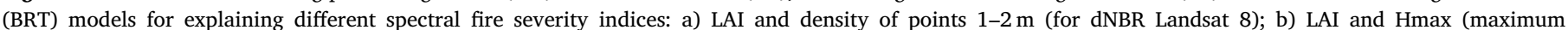

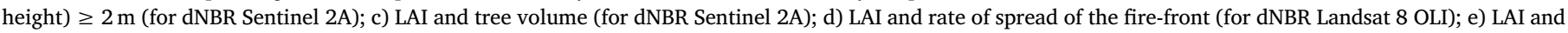
directional slope (for RdNBR Sentinel 2A) and f) LAI and maximum air temperature (for dNBR Sentinel 2A).

Vegetation biomass (i.e., LAI/fPAR) interacted with burning conditions, especially in the RdNBR models. Hence, for burned stands with LAI/ fPAR held constant, fire severity was higher in sites where the rate of spread of the fire-front was higher and fire spread upslope under high air temperature (Fig. 11).

There were several important interacions among burning condition variables (SM Table 4 and Fig. 12). Directional slopes interacted with aligned winds and maximum air temperature. Accordingly, areas that burned under higher fire severity were those located uphill of the firefront, under high fire-aligned winds and high air temperature. Also, the rate of spread of the fire-front interacted with maximum air temperature, as well as with the density of points $1-2 \mathrm{~m}$ and intensity standard deviation of points $<2 \mathrm{~m}$. Hence, fire severity increased in areas dominated by high and homogeneous understory vegetation where the rate of spread of the fire-front was high (Fig. 12).

\section{Discussion}

4.1. Do the various severity indices derived from different satellites reflect field-based fire severity equally well?

Our results demonstrate that spectral fire severity indices derived from Sentinel 2A were slightly more accurate in reflecting CBI than indices derived from Landsat 8 OLI, probably due to the higher spatial resolution of Sentinel 2A. This is an important issue for increasing our knowledge about the inter-comparability among satellites. More so given that Sentinel 2 is considered an improvement and a continuity of the Landsat family. Other issue that has attracted some attention lately is what kind of models are used to relate spectral indices and field data. We found that 2nd order polynomial models produced better fits than linear ones, due to the non-linear behaviour and saturation of CBI's highest values (e.g., van Wagtendonk et al., 2004; Veraverbeke et al., 2010; Parks et al., 2014). When we applied the 2nd order polynomial models, they were better predictors of RBR and RdNBR than dNBR, although differences among them were small.

From the classification of spectral fire severity indices based on standard CBI thresholds, we could assess the sensitivity of such indices to different vegetation properties. Here, we observed that RdNBR estimated a larger fractional area at high fire severity than the other indices, mainly because RdNBR was better able to capture biomass loss where pre-fire vegetation cover was low (mainly areas covered by shrubs and herbs) than RBR or dNBR (Parks et al., 2014).

\subsection{What are the relative roles of prefire vegetation and burning conditions} in determining fire severity?

Our work documents that the use of fire progression maps, firealigned slopes and winds, together with high resolution biophysical data can greatly increase the predictability of fire severity derived from spectral indices. Our full BRT models (Adj. $\mathrm{R}^{2}: 86 \% \pm 0.04$ and $68 \% \pm 0.05$ for training and validation data, respectively) were better at predicting fire severity than even the most accurate published models using non-aligned data (e.g., Collins et al., 2007; Fernandes et al., 2010; Birch et al., 2015; Barker and Price, 2018; García-Llamas et al., 2019). 

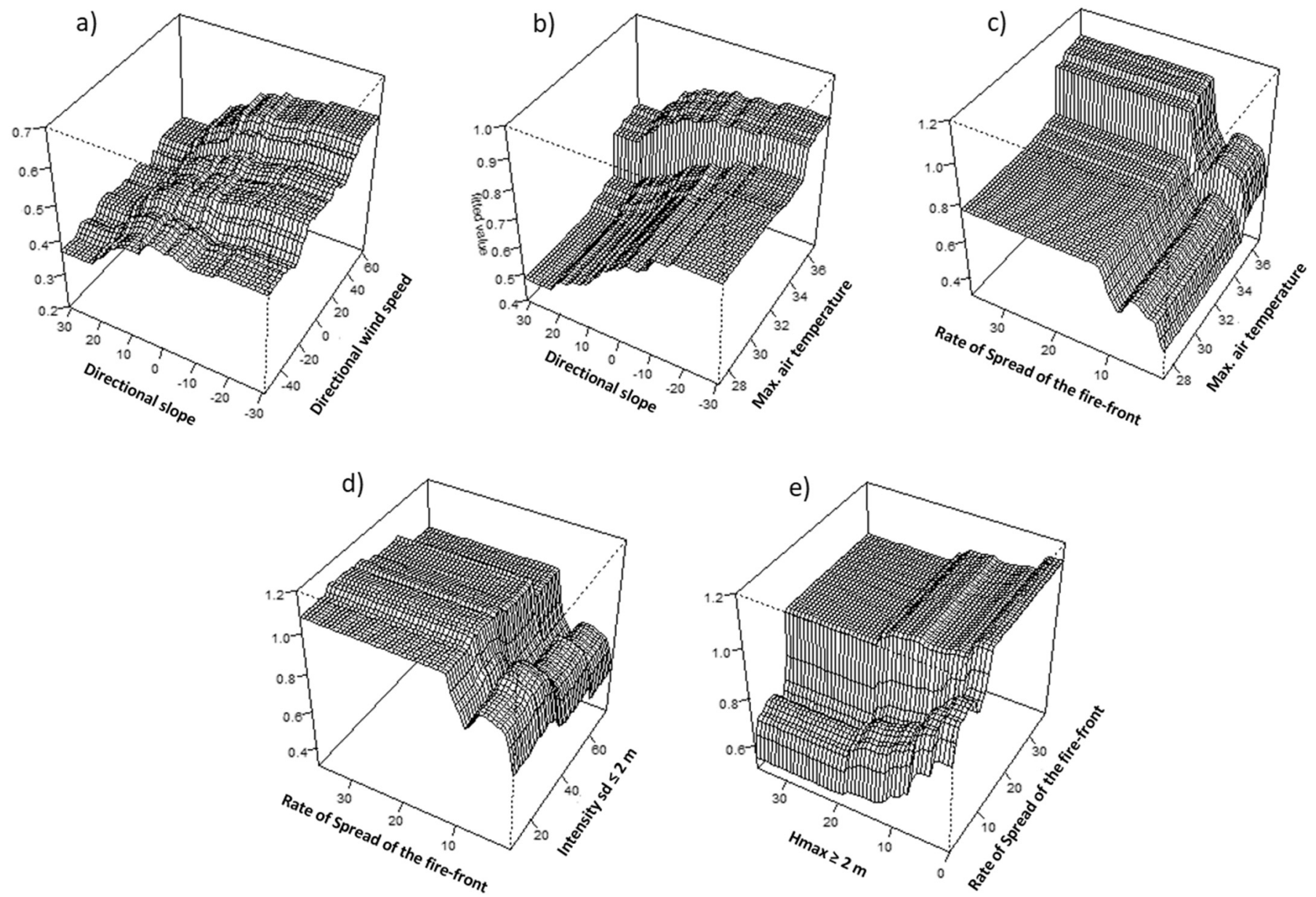

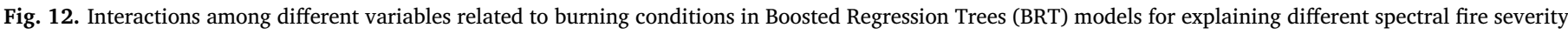

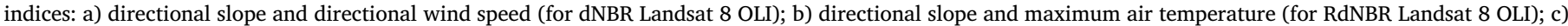

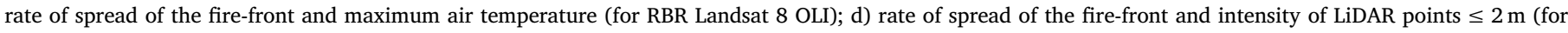
RdNBR Landsat $8 \mathrm{OLI}$ ); and d) rate of spread of the fire-front and maximum height of LiDAR points $>2 \mathrm{~m}$ (for RdNBR Landsat 8 OLI).

Our best full BRT models were those based on all sets of variables, independently of both the spectral fire severity index and the satellite type. Nevertheless, predictive models of dNBR and RBR were slightly better than those of RdNBR, mainly due to the presence of very extreme pixel values. Summaries of the spectral fire severity indices indicated that RdNBR showed very extreme maximum values (21 and 14, for Sentinel 2 and Landsat 8 respectively), which were much higher than RBR (0.71 and 0.65; respectively), and dNBR (1.13 and 1.05; respectively) values. Although such extreme values were not considered in BRT models, RdNBR continued having very high values that were not well accounted for by the models.

We also found that, according to the importance of native variable derived from BRT models, the mean contribution of the variables included under burning conditions was higher than the contribution of both LiDAR metrics and prefire vegetation alone (39.7\% vs. $28.7 \%$ and $21.7 \%$; respectively). This was especially the case for fire severity indices derived from Landsat 8 OLI possibly due to its coarser spatial resolution. The single variables that most contributed to the full BRT models of all spectral indices were: rate of spread of the fire-front, LAIfPAR and understory vegetation (i.e., density of points at 1-2 m). Moreover, using the jaccknife approach, we could honestly assess that burning conditions were the strongest predictor of fire severity followed by LiDAR metrics. From these results, we can infer that even under extreme weather conditions, landscape features can play an important role in determining fire severity.
4.3. What vegetation properties were most closely related to high fire severity? Did the incorporation of LiDAR data significantly improve prediction of fire severity?

Vegetation composition (i.e., dominant and co-dominant species) and vegetation biomass (i.e., based on LAI and fPAR) were very important drivers of fire severity. Scattered trees of Pinus halepensis with shrubs, followed by mixed forests of pines (but always including $P$. halepensis) and treeless shrubs were the vegetation types most severely burned. Pinus pinaster and Pinus nigra were, in contrast, the least severely burned. Moreover, areas with medium-high LAI values (c.a. 1.5) and low fPAR $(<0.2)$ burned with higher severity. Our results concur with works that found that scattered trees with shrubs and treeless shrubs burn at very high severity (e.g., Oliveras et al., 2009; Harris and Taylor, 2015; Estes et al., 2017; Fang et al., 2018; García-Llamas et al., 2019). For example, high severity (RdNBR) areas in the disastrous Portuguese fires of 2017 were mostly constituted by shrublands (Fernandes et al., 2019). Fuel models played a secondary role, mainly because they were overshadowed by other variables related to vegetation composition and structure. These results have important implications, as most current fire behaviour models use fuel models and not actual vegetation data as inputs. The fuel types that burned with higher fire severity were mainly tall shrubs and/or small trees (FM 4), followed by medium shrubs (FM 3) and open forests (FM 8).

In addition, vegetation structure derived from LiDAR data contributed greatly to help explaining how vegetation composition and 
biomass interacted to influence fire severity. BRT models including only prefire vegetation or LiDAR metrics did not show significant differences in any performance measure. However, when both sets of variables were included, model performance increased and was significantly better than models including one set of variables at a time. Stands that burned at high fire severity were typically those with highly heterogeneous tree-height distributions, with high densities of small trees of low volume and crown area, around $5 \mathrm{~m}$ in height, and wide tree spacing. These stands supported a dense understory of shrubs but a patchy overstory (i.e., poor horizontal fuel continuity in the canopy layer) and were less likely to burn as tree-crown fires but readily supported passive crowning (torching) and spotting under low humidities (Ryan, 2002). Accordingly, we found that stands dominated by smaller-diameter trees, with small basal areas and low height supported high severity burning (Alexander et al., 2006; Jain and Graham, 2007; Fernandes et al., 2010; Miller et al., 2012; Viedma et al., 2015). These results were supported by the BRT model based on the underlying factors explaining the spatial variability of LAI (not shown), which was rather well explained by vegetation structure derived from LiDAR metrics (Adj. $\mathrm{R}^{2}$ : $96 \%$ and $88 \%$ for training and validation data; respectively). Higher LAI values - which tended to burn at lower severities - were found in stands with high crown relief ratio (CRR) (i.e., tall canopies), with high numbers of trees between 20 and $25 \mathrm{~m}$ tall and low cover of understory of forbs and shrubs.

\subsection{How is fire severity related to burning conditions?}

BRT models based only on burning conditions were the most accurate partial BRT models based on only one set of variables. Moreover, when burning conditions were included together with prefire vegetation or LiDAR metrics, the performance of the models considerably increased. Fire spread rate was the single most important driver of fire severity $(18.2 \% \pm 6.4)$. The fire spread rate depends on three main factors: fuel biomass, fire weather conditions, and topography (e.g., Moritz et al., 2012; Cruz and Alexander, 2013). Fireline intensity is directly related to rate of spread and fuel load available, which is related to fuel consumption (Andrews, 2018). These results were supported by the BRT model based on the underlying factors explaining the rate of spread of the fire-front (not shown) that was mainly explained by fire weather conditions (i.e., low air relative humidity and high wind speed), directional topography (i.e., uphill slopes), and fuel conditions (i.e., heterogeneous stands [i.e., medium-high Shannon's diversity of height bins] with medium-high LAI and stand dominance by smallmedium trees [6-8 m]). The accuracy of the explanatory models of the rate of spread of the fire-front were very high (Adj. $\mathrm{R}^{2}: 94 \%$ and $78 \%$ for training and validation data; respectively).

Slopes aligned with the fire-front direction played an important role in explaining fire severity in both partial and full BRT models. Higher fire severity was found on steep slopes where fire spread upslope (Viedma et al., 2015). These results indicated that fire behaviour dynamically interacts with topography to influence fire severity. Some other studies have found that the alignment of slopes with wind, without including the fire-front direction, poorly explains fire severity (Lecina-Diaz et al., 2014; Birch et al., 2015; Fernández-Alonso et al., 2017), mainly because slopes aligned with the wind direction are more related to the dominant fire-front direction (Barros et al., 2013) and fire extent (Moritz et al., 2010; Mansuy et al., 2014) than with fire severity. Here, in a further analysis (not shown) we found that standard topographical variables alone (i.e., elevation and slope) explained lower variance than models based on burning conditions alone. Furthermore, full BRT models including standard topography instead of burning conditions explained less variance than those including burning conditions (Adj. R2: $73 \%$ vs $86 \%$ and $46 \%$ vs $68 \%$ for training and validation data, respectively and Moran's index 0.25 vs 0.14 ). Hence, the role of burning conditions (mainly, the rate of the spread of the firefront) was greater than topographical variables alone.
Fire weather conditions (i.e., high winds and high temperature) were major factors in determining fire severity. The alignment of wind direction and speed to the fire-front direction (i.e., directional wind speed) was a relevant driver of fire severity. It was found that high winds blowing both windwad and leeward (this latter especially for RdNBR) increased fire severity. Accordingly, it seems that wind speed was more relevant than wind alignment to the fire-front direction for producing high fire severity. Moreover, a maximum air temperature above $35^{\circ} \mathrm{C}$ was a threshold that produced a significant rise in fire severity (Bradstock et al., 2010). Overall, for fires that are not definitively wind-driven or plume-driven, there can be high variability in the ways and situations that fire weather interacts with topography and vegetation to drive fire severity (Lahaye et al., 2018). For such fires, it would be ideal to have a complete and detailed reconstruction of the fire progression. When high resolution fire progression data are available and hourly weather conditions (including aligned wind speed and direction) can be matched with burning periods, the relative importance of weather conditions in explaining fire severity will likely increase considerably.

As in other studies, fire history played a minor role in explaining fire severity (e.g., Miller et al., 2012; Harris and Taylor, 2015, 2017; Whitman et al., 2018; but see García-Llamas et al., 2019), mainly because it was hidden by LiDAR metrics related to vegetation structure, which better represented the effects of the earlier fire. Nevertheless, we found that areas which burned previously (with a time since the last fire of 23 years), tended to burn with higher severity than areas that did not burn previously (e.g., Clarke et al., 2014). This is largely due to reburned sites having more open spaces, shrubs and young pinus $(P$. halenpensis) trees. Information on the fire severity of the previous fire would probably have made the assessment of fire history effects more robust (see, e.g., Coppoletta et al., 2016).

Our findings are obviously limited by the fact that we studied a single fire. However, over the last 10 years detailed maps of fire-front advance for large fires have started to become available for some countries. This important temporal information will allow revisiting relationships between environmental controls (fuels, topography and weather) and fire spread rates across different ecosystems, contributing to improved fire behaviour models (Veraverbeke et al., 2014).

\subsection{How do prefire vegetation and burning conditions interact in driving fire severity?}

Our study area is very complex topographically with great spatial variability in the vegetation and corresponding fuels, and fire weather was extreme. In this case we determined that fire weather, instead of overriding or reducing the influence of fuels and topography, interacted with local controls to influence fire severity (e.g., Bradstock et al., 2010). We found strong interactions among the drivers of fire severity, mainly between vegetation, fire weather and topography, in accordance with Lee et al. (2008) and Viedma et al. (2015). For stands with medium-high biomass and composed by small trees with homogeneous understory, fire severity was highest where burning occurred upslope with high rate of spread of the fire-front and under high wind and high air temperature. Finally, we found interactions between aligned topography and weather (i.e., directional wind speed and maximum air temperature) such that the same topographic position could have different effects on fire severity under different weather conditions.

\subsection{Management implications}

Fuel management strategies designed to mitigate fire spread may also be successful at decreasing fire severity (Thompson and Spies, 2009; Fernandes et al., 2010; Safford et al., 2012). However, some suggested that under extreme fire weather conditions fuel modifications may be ineffective because burning conditions overwhelm the fuel portion of the fire behaviour triangle (e.g., Bessie and Johnson, 2011; 
Schoennagel et al., 2004). Although such extreme conditions certainly exist, some of this science is based on static and coarse-scale data that may not realistically represent vegetation or burning conditions. Our work found that although burning conditions were more important than vegetation (composition, structure and fuel types) in driving fire severity, prefire vegetation continued being significant in explaining fire severity even under the extreme fire weather of this fire. We concur with studies that suggest that vegetation manipulation can play an important role in determining the outcome of even extreme wildfires. In forested landscaspes, fire-smart silviculture should be oriented to decrease the accumulation of surface fuels, raising the canopy base by pruning trees and reducing the density of ladder fuels while mantaining large trees, and promoting canopy characteristics that reduce continuity but also maintain sufficient shade to limit understory fuels (Agee and Skinner, 2005; Fernandes and Rigolot, 2007; Fernandes, 2013). Of course, the effects of fuel treatments on fire behaviour are only temporary, due to fuel accumulation and long-term changes in fuel-bed structure, and the ability of treatments to influence fire severity will be reduced in the absence of continued management (Fulé et al., 2001).

\section{Conclusion}

We found that the Sentinel 2A satellite better explained field fireseverity metrics (i.e., CBI) than Landsat 8 OLI. Additional, second order polynomial models better explained these relationships than linear regression models. RBR fitted field-based fire severity metrics slightly better than RdNBR, and particularly, than dNBR. RdNBR was more sensitive than RBR and dNBR to biomass loss in shrublands and to areas with low vegetation cover, thus measuring a higher proportion of areas burned at high fire severity than the other indices. Full BRT models used to explain the spatial variability of the three indices showed that there were not significant differences among indices or satellites in performance measures, although RdNBR had the lowest accuracy due to the presence of very extreme pixel values. When each set of variables were considered separately in BRT models, burning conditions alone explained the largest proportion of the fire severity variance followed by LiDAR metrics. When all sets were combined, a large fraction of the variance could be explained (mean Adj. $\mathrm{R}^{2}=86 \%$ and $68 \%$ for training and validation data, respectively). This suggests that in areas with complex topography or large spatial variability in vegetation, fire weather, instead of overriding or reducing the influence of vegetation and topography, interacts with local controls to influence fire severity. Additional models used to explain the underlying factors that are behind the main drivers of fire severity (i.e., LAI and rate of spread of the fire-front) confirmed strong interactions among variables and gave us a better understanding of fire behaviour. Fire severity greatly increased when the rate of spread of the fire-front was high and the fire spread uphill, with high winds blowing in alignment with or against the firefront and under high air temperature. Moreover, fire severity increased in areas with medium biomass, composed by scattered trees of Pinus halepensis with shrubs, followed by mixed forests of Pinus and treeless shrubby areas. Here we have shown that the use of higher resolution satellite imagery (spatial), LiDAR (structural), and fire progression (temporal) information can greatly enhance our ability to predict fire severity on the landscape. As these and other higher resolution datasets are incorporated into fire simulations and forecasting, our ability to modify fuels and make fire-safe landuse decisions on fire-prone landscapes will be notably improved.

\section{Funding}

This research was part of the FOCCLIM project (CGL2016-78357R), funded by the Spanish Ministerio de Economía y Competitividad. We thank to Magi Franquesa for his help in processing Sentinel 2 MSI images and in field campaigns. We highly appreciate the work of the reviewers fot their valuable input to this submission.

\section{Author contributions}

O.V. Performed research, analyzed data and wrote the paper. J.M.M. Conceived and designed the study and wrote the paper. F.C., J.J.F. and C.M. developed fire behaviour and the fire progression map and wrote the paper. H.S. wrote the paper.

\section{Appendix A. Supplementary data}

Supplementary data to this article can be found online at https:// doi.org/10.1016/j.rse.2020.111891.

\section{References}

Agee, J.K., Skinner, C.N., 2005. Basic principles of forest fuel reduction treatments. For. Ecol. Manag. 211, 83-96. https://doi.org/10.1016/J.FORECO.2005.01.034.

Agee, J.K., Wright, C.S., Williamson, N., Huff, M.H., 2002. Foliar moisture content of Pacific northwest vegetation and its relation to wildland fire behavior. For. Ecol. Manag. 167, 57-66. https://doi.org/10.1016/S0378-1127(01)00690-9.

Alexander, J.D., Seavy, N.E., Ralph, C.J., Hogoboom, B., 2006. Vegetation and topographical correlates of fire severity from two fires in the Klamath-Siskiyou region of Oregon and California. Int. J. Wildland Fire 15, 237. https://doi.org/10.1071/ WF05053.

Allen, J.L., Sorbel, B., 2008. Assessing the differenced normalized burn Ratio's ability to map burn severity in the boreal forest and tundra ecosystems of Alaska's national parks. Int. J. Wildland Fire 17, 463-475. https://doi.org/10.1071/WF08034.

Amraoui, M., Pereira, M.G., DaCamara, C.C., Calado, T.J., 2015. Atmospheric conditions associated with extreme fire activity in the Western Mediterranean region. Sci. Total Environ. 524-525, 32-39. https://doi.org/10.1016/j.scitotenv.2015.04.032.

Andrews, P.L., 2018. The Rothermel surface fire spread model and associated developments: a comprehensive explanation. Gen. Tech. Rep. 121 RMRS-GTR-371.

Bar Massada, A., Syphard, A.D., Stewart, S.I., Radeloff, V.C., 2012. Wildfire ignitiondistribution modelling: a comparative study in the Huron-Manistee National Forest, Michigan, USA. Int. J. Wildland Fire 22, 174-183. https://doi.org/10.1071/ WF11178.

Barker, J.W., Price, O.F., 2018. Positive severity feedback between consecutive fires in dry eucalypt forests of southern Australia. Ecosphere 9. https://doi.org/10.1002/ ecs2.2110.

Barros, A.M.G., Pereira, J.M.C., Moritz, M.A., Stephens, S.L., 2013. Spatial characterization of wildfire orientation patterns in California. Forests 4, 197-217. https://doi. org/10.3390/f4010197.

Bessie, A.W.C., Johnson, E.A., 2011. The relative importance of fuels and weather on fire behavior in subalpine forests. Ecology 76, 747-762. https://doi.org/10.2307/ 1939341.

Birch, D.S., Morgan, P., Kolden, C.A., Abatzoglou, J.T., Dillon, G.K., Hudak, A.T., Smith, A.M.S., 2015. Vegetation, topography and daily weather influenced burn severity in Central Idaho and western Montana forests. Ecosphere 6https://doi.org/10.1890/ es14-00213.1. art17.

Bradstock, R.A., Hammill, K.A., Collins, L., Price, O., 2010. Effects of weather, fuel and terrain on fire severity in topographically diverse landscapes of South-Eastern Australia. Landsc. Ecol. 25, 607-619. https://doi.org/10.1007/s10980-009-9443-8.

Broncano, M., Retana, J., 2004. Topography and forest composition affecting the variability in fire severity and post-fire regeneration occurring after a large fire in the Mediterranean basin. Int. J. Wildland Fire 209-216. https://doi.org/10.1071/ WF03036.

Camia, A., Bovio, G., Aguado, I., Stach, N., 1999. Meteorological fire danger indices and remote sensing. In: Chuvieco, E. (Ed.), Remote Sensing of Large Wildfires. Springer, Berlin, Heidelberg. https://doi.org/10.1007/978-3-642-60164-4_4.

Cansler, C.A., McKenzie, D., 2012. How robust are burn severity indices when applied in a new region? Evaluation of alternate field-based and remote-sensing methods. Remote Sens. 4, 456-483. https://doi.org/10.3390/rs4020456.

Clarke, P.J., Lawes, M.J., Midgley, J.J., Lamont, B.B., Ojeda, F., Burrows, G.E., Enright, N.J., Knox, K.J.E., 2013. Resprouting as a key functional trait: how buds, protection and resources drive persistence after fire. New Phytol. 197, 19-35. https://doi.org/ 10.1111/nph.12001.

Clarke, P.J., Knox, K.J.E., Bradstock, R.A., Munoz-Robles, C., Kumar, L., 2014. Vegetation, terrain and fire history shape the impact of extreme weather on fire severity and ecosystem response. J. Veg. Sci. 25, 1033-1044. https://doi.org/10.1111/ jvs.12166.

Coen, J.L., Stavros, E.N., Fites-Kaufman, J.A., 2018. Deconstructing the king megafire. Ecol. Appl. 28, 1565-1580. https://doi.org/10.1002/eap.1752.

Collins, B.M., Kelly, M., Van Wagtendonk, J.W., Stephens, S.L., 2007. Spatial patterns of large natural fires in Sierra Nevada wilderness areas. Landsc. Ecol. 22, 545-557. https://doi.org/10.1007/s10980-006-9047-5.

Collins, L., Bennett, A.F., Leonard, S.W.J., Penman, T.D., 2019. Wildfire refugia in forests: severe fire weather and drought mute the influence of topography and fuel age. Glob. Chang. Biol. 0-1. https://doi.org/10.1111/gcb.14735.

Conard, S.G., Sukhinin, A.I., Stocks, B.J., Cahoon, D.R., Davidenko, E.P., Ivanova, G.A., 2002. Determining effects of area burned and fire severity on carbon cycling and emissions in Siberia. Clim. Chang. 55, 197-211. https://doi.org/10.1023/ A:1020207710195. 
Coppoletta, M., Merriam, K.E., Collins, B.M., 2016. Post-fire vegetation and fuel development influences fire severity patterns in reburns. Ecol. Appl. 26, 686-699. https:// doi.org/10.1890/15-0225.

Core Team, R., 2017. R: A language and environment for statistical computing. In: R Foundation for Statistical Computing,Vienna, Austria, URL. https://www.R-project. org/.

Cruz, M.G., Alexander, M.E., 2013. Uncertainty associated with model predictions of surface and crown fire rates of spread. Environ. Model. Softw. 47, 16-28. https://doi. org/10.1016/j.envsoft.2013.04.004.

DeSiervo, M.H., Jules, E.S., Safford, H.D., 2015. Disturbance response across a productivity gradient: postfire vegetation in serpentine and nonserpentine forests. Ecosphere 6https://doi.org/10.1890/ES14-00431.1. art60.

Dillon, G.K., Holden, Z.A., Morgan, P., Crimmins, M.A., Heyerdahl, E.K., Luce, C.H., 2011. Both topography and climate affected forest and woodland burn severity in two regions of the western US, 1984 to 2006. Ecosphere 2https://doi.org/10.1890/ES1100271.1. art130.

Doerr, S.H., Shakesby, R.A., Blake, W.H., Chafer, C.J., Humphreys, G.S., Wallbrink, P.J., 2006. Effects of differing wildfire severities on soil wettability and implications for hydrological response. J. Hydrol. 319, 295-311. https://doi.org/10.1016/j.jhydrol. 2005.06.038.

Elith, J., Leathwick, J.R., Hastie, T., 2008. A working guide to boosted regression trees. J. Anim. Ecol. 77, 802-813. https://doi.org/10.1111/j.1365-2656.2008.01390.x.

Estes, B.L., Knapp, E.E., Skinner, C.N., Miller, J.D., Preisler, H.K., 2017. Factors influencing fire severity under moderate burning conditions in the Klamath Mountains, northern California, USA. Ecosphere 8. https://doi.org/10.1002/ecs2.1794.

Fang, L., Yang, J., Zu, J., Li, G., Zhang, J., 2015. Quantifying influences and relative importance of fire weather, topography, and vegetation on fire size and fire severity in a Chinese boreal forest landscape. For. Ecol. Manag. 356, 2-12. https://doi.org/10. 1016/J.FORECO.2015.01.011

Fang, L., Yang, J., White, M., Liu, Z., 2018. Predicting potential fire severity using vegetation, topography and surface moisture availability in a Eurasian boreal forest landscape. Forests 9. https://doi.org/10.3390/f9030130.

Fernandes, P.M., 2013. Fire-smart management of forest landscapes in the Mediterranean basin under global change. Landsc. Urban Plan. 110, 175-182. https://doi.org/10. 1016/j.landurbplan.2012.10.014

Fernández-García, V., Santamarta, M., Fernández-Manso, A., Quintano, C., Marcos, E., Calvo, L., 2018. Burn severity metrics in fire-prone pine ecosystems along a climatic gradient using Landsat imagery. Remote Sensing of Environment 206, 205-217.

Fernandes, P.M., Rigolot, E., 2007. The fire ecology and management of maritime pine (Pinus pinaster ait.). For. Ecol. Manag. 241, 1-13. https://doi.org/10.1016/j.foreco. 2007.01.010.

Fernandes, P.A.M., Loureiro, C.A., Botelho, H.S., 2004. Fire behaviour and severity in a maritime pine stand under differing fuel conditions. Ann. For. Sci. 61, 1-16. https:// doi.org/10.1051/forest:2004048.

Fernandes, P.M., Luz, A., Loureiro, C., 2010. Changes in wildfire severity from maritime pine woodland to contiguous forest types in the mountains of northwestern Portugal. For. Ecol. Manag. 260, 883-892. https://doi.org/10.1016/J.FORECO.2010.06.008.

Fernandes, P.M., Guiomar, N., Rossa, C.G., 2019. Analysing eucalypt expansion in Portugal as a fire-regime modifier. Sci. Total Environ. 666, 79-88. https://doi.org/ 10.1016/j.scitotenv.2019.02.237.

Fernández-Alonso, J.M., Vega, J.A., Jiménez, E., Ruiz-González, A.D., Álvarez-González, J.G., 2017. Spatially modeling wildland fire severity in pine forests of Galicia, Spain. Eur. J. For. Res. 136, 105-121. https://doi.org/10.1007/s10342-016-1012-5.

Forthofer, J.M., 2007. Modeling wind in complex terrain for use in fire spread prediction. Masters thesis. Colorado State University, USA, pp. 123.

Fulé, P.Z., Waltz, A.E.M., Covington, W.W., Heinlein, T.A., 2001. Measuring Forest restoration effectiveness in reducing hazardous fuels. J. For. 99, 24-29. https://doi. org/10.1093/jof/99.11.24.

García-Llamas, P., Suárez-Seoane, S., Taboada, A., Fernández-Manso, A., Quintano, C. Fernández-García, V., Fernández-Guisuraga, J.M., Marcos, E., Calvo, L., 2019. Environmental drivers of fire severity in extreme fire events that affect Mediterranean pine forest ecosystems. For. Ecol. Manag. 433, 24-32. https://doi.org/10.1016/J. FORECO.2018.10.051

González, J.R., Trasobares, A., Palahí, M., Pukkala, T., 2007. Predicting stand damage and tree survival in burned forests in Catalonia (north-East Spain). Ann. For. Sci. 64 733-742. https://doi.org/10.1051/forest:2007053.

Hammill, K.A., Bradstock, R.A., 2006. Spatial patterns of fire behaviour in relation to weather, terrain and vegetation. Proc. R. Soc. Queensl. 115, 129-135 ST.

Harris, L., Taylor, A., 2015. Topography, fuels, and fire exclusion drive fire severity of the rim fire in an old-growth mixed-conifer Forest, Yosemite National Park, USA. Ecosystems 1-17. https://doi.org/10.1007/s10021-015-9890-9.

Harris, L., Taylor, A.H., 2017. Previous burns and topography limit and reinforce fire severity in a large wildfire. Ecosphere 8. https://doi.org/10.1002/ecs2.2019.

Harris, L.B., Scholl, A.E., Young, A.B., Estes, B.L., Taylor, A.H., 2019. Spatial and temporal dynamics of 20th century carbon storage and emissions after wildfire in an oldgrowth forest landscape. For. Ecol. Manag. 449, 117461. https://doi.org/10.1016/J. FORECO.2019.117461.

Harvey, B.J., Andrus, R.A., Anderson, S.C., 2019. Incorporating biophysical gradients and uncertainty into burn severity maps in a temperate fire-prone forested region. Ecosphere 10. https://doi.org/10.1002/ecs2.2600.

Hijmans, R.J., van Etten, J., 2012. Raster: geographic analysis and modeling with raster data. $\mathrm{R}$ package version. 2. pp. $0-12$

Holden, Z.A., Morgan, P., Evans, J.S., 2009. A predictive model of burn severity based on 20 -year satellite-inferred burn severity data in a large southwestern US wilderness area. For. Ecol. Manag. 258, 2399-2406. https://doi.org/10.1016/j.foreco.2009.08 017.
Jain, T., Graham, R., 2007. The relation between tree burn severity and forest structure in the Rocky Mountains-USDA Forest Service. Gen. Tech. Rep. 2007 PSW-GTR-203.

Jones, B.M., Kolden, C.A., Jandt, R., Abatzoglou, J.T., Urban, F., Arp, C.D., 2009. Fire behavior, weather, and burn severity of the 2007 Anaktuvuk River tundra fire, north slope, Alaska. Arctic. Antarct. Alp. Res. 41, 309-316. https://doi.org/10.1657/19384246-41.3.309.

Keeley, J.E., 2009. Fire intensity, fire severity and burn severity: a brief review and suggested usage. Int. J. Wildland Fire 18, 116. https://doi.org/10.1071/WF07049.

Key, C.H., Benson, N.C., 2006. Landscape assessment (LA): sampling and analysis methods. USDA For. In: Serv. Gen. Tech. Rep. RMRS- GTR-164-CD. LA1-LA51. USDA For. Serv. Rocky Mt. Res. Stn, pp. 1-55. https://doi.org/10.1002/app.1994. 070541203.

Khosravipour, A., Skidmore, A.K., Isenburg, M., 2016. Generating spike-free digital surface models using LiDAR raw point clouds: a new approach for forestry applications. Int. J. Appl. Earth Obs. Geoinf. 52, 104-114. https://doi.org/10.1016/J.JAG.2016. 06.005 .

Kindt, R., Coe, R., 2005. Tree diversity analysis. In: A Manual and Software for Common Statistical Methods for Ecological and Biodiversity Studies. World Agroforestry Centre (ICRAF), Nairobi ISBN 92-9059-179-X.

Lahaye, S., Curt, T., Fréjaville, T., Sharples, J., Paradis, L., Hély, C., 2018. What are the drivers of dangerous fires in Mediterranean France? Int. J. Wildl. Fire 27, 155-163. https://doi.org/10.1071/WF17087.

Lecina-Diaz, J., Alvarez, A., Retana, J., 2014. Extreme fire severity patterns in topographic, convective and wind-driven historical wildfires of Mediterranean pine forests. PLoS One 9, e85127. https://doi.org/10.1371/journal.pone.0085127.

Lee, B., Kim, S.Y., Chung, J., Park, P.S., 2008. Estimation of fire severity by use of Landsa TM images and its relevance to vegetation and topography in the 2000 Samcheok forest fire. J. For. Res. 13, 197-204. https://doi.org/10.1007/s10310-008-0072-x.

Lentile, L.B., Holden, Z.A., Smith, A.M.S., Falkowski, M.J., Hudak, A.T., Morgan, P., Lewis, S.A., Gessler, P.E., Benson, N.C., 2006. Remote sensing techniques to assess active fire characteristics and post-fire effects. Int. J. Wildland Fire 15, 319. https:// doi.org/10.1071/WF05097.

Lindner, M., Maroschek, M., Netherer, S., Kremer, A., Barbati, A., Garcia-Gonzalo, J., Seidl, R., Delzon, S., Corona, P., Kolström, M., Lexer, M.J., Marchetti, M., 2010. Climate change impacts, adaptive capacity, and vulnerability of European forest ecosystems. For. Ecol. Manag. 259, 698-709. https://doi.org/10.1016/J.FORECO 2009.09.023.

Mallek, C., Safford, H., Viers, J., Miller, J., 2013. Modern departures in fire severity and area vary by forest type, Sierra Nevada and southern cascades, California, USA. Ecosphere 4https://doi.org/10.1890/ES13-00217.1. art153.

Mallinis, G., Mitsopoulos, I., Chrysafi, I., 2018. Evaluating and comparing sentinel 2A and Landsat- 8 operational land imager (OLI) spectral indices for estimating fire severity in a mediterranean pine ecosystem of Greece. GIScience Remote Sens. 55, 1-18. https://doi.org/10.1080/15481603.2017.1354803.

Mansuy, N., Boulanger, Y., Terrier, A., Gauthier, S., Robitaille, A., Bergeron, Y., 2014. Spatial attributes of fire regime in eastern Canada: influences of regional landscape physiography and climate. Landsc. Ecol. 29, 1157-1170. https://doi.org/10.1007/ s10980-014-0049-4.

Marino, E., Ranz, P., Tomé, J.L., Noriega, M.Á., Esteban, J., Madrigal, J., 2016. Generation of high-resolution fuel model maps from discrete airborne laser scanner and Landsat-8 OLI: a low-cost and highly updated methodology for large areas. Remote Sens. Environ. 187, 267-280. https://doi.org/10.1016/j.rse.2016.10.020.

Marion, G.M., Moreno, J.M., Oechel, W.C., 1991. Fire severity, ash deposition, and clipping effects on soil nutrients in chaparral. Soil Sci. Soc. Am. J. 55, 235-240. https://doi.org/10.2136/sssaj1991.03615995005500010040x.

Meigs, G.W., Donato, D.C., Campbell, J.L., Martin, J.G., Law, B.E., 2009. Forest fire impacts on carbon uptake, storage, and emission: the role of burn severity in the eastern cascades, Oregon. Ecosystems 12, 1246-1267. https://doi.org/10.1007/s10021-0099285-x.

Miller, J.D., Thode, A.E., 2007. Quantifying burn severity in a heterogeneous landscape with a relative version of the delta normalized burn ratio (dNBR). Remote Sens. Environ. 109, 66-80. https://doi.org/10.1016/j.rse.2006.12.006.

Miller, J.D., Safford, H.D., Crimmins, M., Thode, A.E., 2009. Quantitative evidence for increasing forest fire severity in the Sierra Nevada and southern Cascade Mountains, California and Nevada, USA. Ecosystems 12, 16-32. https://doi.org/10.1007/ s10021-008-9201-9.

Miller, J.D., Skinner, C.N., Safford, H.D., Knapp, E.E., Ramirez, C.M., 2012. Trends and causes of severity, size, and number of fires in northwestern California, USA. Ecol. Appl. 22, 184-203. https://doi.org/10.1890/10-2108.1.

Miller, J.E.D., Root, H.T., Safford, H.D., 2018. Altered fire regimes cause long-term lichen diversity losses. Glob. Chang. Biol. 24, 4909-4918. https://doi.org/10.1111/gcb. 14393.

Moreno, J.M., Oechel, W.C., 1989. A simple method for estimating fire intensity after a burn in California chaparral. Acta Oecologica (Oecologia Plantarum) 10, 57-68.

Moreno, J.M., Oechel, W.C., 1993. Demography of Adenostoma fasciculatum after fires of different intensities in southern California chaparral. Oecologia 96, 95-101. https:// doi.org/10.1007/BF00318035.

Morgan, P., Keane, R.E., Dillon, G.K., Jain, T.B., Hudak, A.T., Karau, E.C., Sikkink, P.G., Holden, Z.A., Strand, E.K., 2014. Challenges of assessing fire and burn severity using field measures, remote sensing and modelling. Int. J. Wildland Fire 23, 1045. https:// doi.org/10.1071/wf13058.

Moritz, M.A., Moody, T.J., Krawchuk, M.A., Hughes, M., Hall, A., 2010. Spatial variation in extreme winds predicts large wildfire locations in chaparral ecosystems. Geophys. Res. Lett. 37, L04801. https://doi.org/10.1029/2009GL041735.

Moritz, M.A., Parisien, M.-A., Batllori, E., Krawchuk, M.A., Van Dorn, J., Ganz, D.J., Hayhoe, K., 2012. Climate change and disruptions to global fire activity. Ecosphere 3 , 
1-22. https://doi.org/10.1890/es11-00345.1.

Oliveras, I., Gracia, M., Moré, G., Retana, J., 2009. Factors influencing the pattern of fire severities in a large wildfire under extreme meteorological conditions in the Mediterranean basin. Int. J. Wildland Fire 18, 755. https://doi.org/10.1071/ WF08070.

Parker, G.G., Russ, M.E., 2004. The canopy surface and stand development: assessing forest canopy structure and complexity with near-surface altimetry. For. Ecol. Manag. 189, 307-315. https://doi.org/10.1016/J.FORECO.2003.09.001.

Parks, S.A., Dillon, G.K., Miller, C., 2014. A new metric for quantifying burn severity: the relativized burn ratio. Remote Sens. 6, 1827-1844. https://doi.org/10.3390/ rs6031827.

Parks, S.A., Holsinger, L.M., Miller, C., Nelson, C.R., 2015. Wildland fire as a self-regulating mechanism: the role of previous burns and weather in limiting fire progression. Ecol. Appl. 25, 1478-1492.

Parks, S., Holsinger, L., Panunto, M., Jolly, W.M., Dobrowski, S., Dillon, G., 2018. High severity fire: evaluating its key drivers and mapping its probability across western US forests. Environ. Res. Lett. https://doi.org/10.1088/1748-9326/aab791.

Pereira, M.G., Trigo, R.M., da Camara, C.C., Pereira, J.M.C., Leite, S.M., 2005. Synoptic patterns associated with large summer forest fires in Portugal. Agric. For. Meteorol. $129,11-25$.

Pérez, B., Moreno, J.M., 1998. Methods for quantifying fire severity in shrubland-fires. Plant Ecol. 139, 91-101.

Price, O.F., Bradstock, R.A., 2012. The efficacy of fuel treatment in mitigating property loss during wildfires: insights from analysis of the severity of the catastrophic fires in 2009 in Victoria, Australia. J. Environ. Manag. https://doi.org/10.1016/j.jenvman. 2012.08.041.

PSP, 1999. Prometheus, S.V., Project, 1999. Management techniques for optimisation of suppression and minimization of wildfire effects. In: System Validation. European Commission, Contract Number ENV4-CT98-0716.

Rapidlasso, GmbH, 2019. LAStools Rapid LiDAR Processing. URL. http://www. rapidlasso.com Sommerhausen, Germany, (last data accessed: 30.06.19.).

Riaño, D., Chuvieco, E., Salas, J., Palacios-Orueta, A., Bastarrika, A., 2002. Generation of fuel type maps from Landsat TM images and ancillary data in Mediterranean ecosystems. Can. J. For. Res. 32, 1301-1315. https://doi.org/10.1139/x02-052.

Ridgeway, G., 2007. Generalized boosted models: a guide to the gbm package. Update 1 (1).

Robichaud, P.R., 2009. Post-fire stabilization and rehabilitation. In: Cerdà, A., Robichaud, P.R. (Eds.), Fire Effects on Soils and Restoration Strategies. CRC Press. Oxford, UK, pp. 299-320.

Román-Cuesta, R.M., Gracia, M., Retana, J., 2009. Factors influencing the formation of unburned forest islands within the perimeter of a large forest fire. For. Ecol. Manag. 258, 71-80. https://doi.org/10.1016/j.foreco.2009.03.041.

Roussel, J.R., Auty, D., 2018. lidR: Airborne LiDAR Data Manipulation and Visualization for Forestry Applications. R package version 1.0. 0.

Ryan, K.C., 2002. Dynamic interactions between Forest structure and fire behavior in boreal ecosystems Silva Fennica 36(1) review articles. Silva Fenn. 36, 13-39.

Safford, H.D., Miller, J., Schmidt, D., Roath, B., Parsons, A., 2008. BAER soil burn severity maps do not measure fire effects to vegetation: a comment on Odion and Hanson (2006). Ecosystems 11, 1-11. https://doi.org/10.1007/s10021-007-9094-z.

Safford, H.D., Stevens, J.T., Merriam, K., Meyer, M.D., Latimer, A.M., 2012. Fuel treatment effectiveness in California yellow pine and mixed conifer forests. For. Ecol. Manag. 274, 17-28. https://doi.org/10.1016/J.FORECO.2012.02.013.

Schoennagel, T., Veblen, T.T., Romme, W.H., 2004. The interaction of fire, fuels, and climate across Rocky Mountain forests. Bioscience 54, 661-676. https://doi.org/10. 1641/0006-3568(2004)054[0661:TIOFFA]2.0.CO;2.

Shakesby, R.A., Chafer, C.J., Doerr, S.H., Blake, W.H., Wallbrink, P., Humphreys, G.S., Harrington, B.A., 2003. Fire severity, water Repellency characteristics and Hydrogeomorphological changes following the Christmas 2001 Sydney Forest fires. Aust. Geogr. 34, 147-175. https://doi.org/10.1080/00049180301736.

Shive, K.L., Preisler, H.K., Welch, K.R., Safford, H.D., Butz, R.J., O'Hara, K.L., Stephens, S.L., 2018. From the stand scale to the landscape scale: predicting the spatial patterns of forest regeneration after disturbance. Ecol. Appl. 28, 1626-1639. https://doi.org/ 10.1002/eap.1756

Silva, C.A., Hudak, A.T., Vierling, L.A., Klauberg, C., García, M., Ferraz, A., Keller, M., Eitel, J., Saatchi, S., 2017. Impacts of airborne LiDAR pulse density on estimating biomass stocks and changes in a selectively logged tropical forest. Remote Sens. 9. https://doi.org/10.3390/rs9101068.

Steel, Z.L., Safford, H.D., Viers, J.H., 2015. The fire frequency-severity relationship and the legacy of fire suppression in California forests. Ecosphere 6https://doi.org/10. 1890/ES14-00224.1. art8.

Steel, Z.L., Koontz, M.J., Safford, H.D., 2018. The changing landscape of wildfire: burn pattern trends and implications for California's yellow pine and mixed conifer forests. Landsc. Ecol. 33, 1159-1176. https://doi.org/10.1007/s10980-018-0665-5.

Thompson, J.R., Spies, T.A., 2009. Vegetation and weather explain variation in crown damage within a large mixed-severity wildfire. For. Ecol. Manag. 258, 1684-1694. https://doi.org/10.1016/j.foreco.2009.07.031.

Thompson, J.R., Spies, T.A., 2010. Factors associated with crown damage following recurring mixed-severity wildfires and post-fire management in southwestern Oregon. Landsc. Ecol. 25, 775-789. https://doi.org/10.1007/s10980-010-9456-3.

Trigo, R.M., Pereira, J.M.C., Pereira, M.G., Mota, B., Calado, T.J., DaCamara, C.C., Santo, F.E., 2006. Atmospheric conditions associated with the exceptional fire season of 2003 in Portugal. Int. J. Climatol. 26, 1741-1757.

Turner, M.G., Hargrove, W.W., Gardner, R.H., Romme, W.H., 1994. Effects of fire on landscape heterogeneity in Yellowstone National Park, Wyoming. J. Veg. Sci. 5, 731-742. https://doi.org/10.2307/3235886.

van Wagtendonk, J.W., Root, R.R., Key, C.H., 2004. Comparison of AVIRIS and Landsat ETM + detection capabilities for burn severity. Remote Sens. Environ. 92, 397-408. https://doi.org/10.1016/j.rse.2003.12.015.

van Wagtendonk, J.W., van Wagtendonk, K.A., Thode, A.E., 2012. Factors associated with the severity of intersecting fires in Yosemite National Park, California, USA. Fire Ecol. 8, 11-31. https://doi.org/10.4996/fireecology.0801011.

Veraverbeke, S., Verstraeten, W., Lhermite, S., Goossens, R., 2010. Evaluating Landsat thematic mapper spectral indices for estimating burn severity of the 2007 Peloponnese wildfires in Greece. Int. J. Wildland Fire 19, 558-569. https://doi.org/ 10.1071/WF09069.

Veraverbeke, S., Sedano, F., Hook, S.J., Randerson, J.T., Jin, Y., Rogers, B.M., 2014 Mapping the daily progression of large wildland fires using MODIS active fire data. Int. J. Wildland Fire 23, 655-667. https://doi.org/10.1071/WF13015.

Veraverbeke, S., Rogers, B.M., Randerson, J.T., 2015. Daily burned area and carbon emissions from boreal fires in Alaska. Biogeosciences 12, 3579-3601. https://doi. org/10.5194/bg-12-3579-2015.

Viedma, O., Quesada, J., Torres, I., De Santis, A., Moreno, J.M., 2015. Fire severity in a large fire in a Pinus pinaster forest is highly predictable from burning conditions, stand structure, and topography. Ecosystems 18, 237-250. https://doi.org/10.1007/ s10021-014-9824-y.

Welch, K.R., Safford, H.D., Young, T.P., 2016. Predicting conifer establishment post wildfire in mixed conifer forests of the north American Mediterranean-climate zone. Ecosphere 7, e01609. https://doi.org/10.1002/ecs2.1609.

White, A.M., Manley, P.N., Tarbill, G.L., Richardson, T.W., Russell, R.E., Safford, H.D., Dobrowski, S.Z., 2016. Avian community responses to post-fire forest structure: implications for fire management in mixed conifer forests. Anim. Conserv. 19, 256-264. https://doi.org/10.1111/acv.12237.

Whitman, E., Parisien, M.A., Thompson, D.K., Hall, R.J., Skakun, R.S., Flannigan, M.D., 2018. Variability and drivers of burn severity in the northwestern Canadian boreal forest. Ecosphere 9. https://doi.org/10.1002/ecs2.2128.

Wulder, M.A., White, J.C., Alvarez, F., Han, T., Rogan, J., Hawkes, B., 2009. Characterizing boreal forest wildfire with multi-temporal Landsat and LIDAR data. Remote Sens. Environ. 113, 1540-1555. https://doi.org/10.1016/j.rse.2009.03.004.

Yebra, M., Chuvieco, E., Riaño, D., 2008. Estimation of live fuel moisture content from MODIS images for fire risk assessment. Agric. For. Meteorol. 148, 523-536. https:// doi.org/10.1016/j.agrformet.2007.12.005.

Zald, H.S.J., Dunn, C.J., 2018. Severe fire weather and intensive forest management increase fire severity in a multi-ownership landscape. Ecol. Appl. 28, 1068-1080. https://doi.org/10.1002/eap.1710. 